\title{
Jet Noise Scaling in Dual Stream Nozzles
}

Abbas Khavaran

ASRC Aerospace Corporation, Cleveland, Ohio

James Bridges

Glenn Research Center, Cleveland, Ohio 


\section{NASA STI Program . . . in Profile}

Since its founding, NASA has been dedicated to the advancement of aeronautics and space science. The NASA Scientific and Technical Information (STI) program plays a key part in helping NASA maintain this important role.

The NASA STI Program operates under the auspices of the Agency Chief Information Officer. It collects, organizes, provides for archiving, and disseminates NASA's STI. The NASA STI program provides access to the NASA Aeronautics and Space Database and its public interface, the NASA Technical Reports Server, thus providing one of the largest collections of aeronautical and space science STI in the world. Results are published in both non-NASA channels and by NASA in the NASA STI Report Series, which includes the following report types:

- TECHNICAL PUBLICATION. Reports of completed research or a major significant phase of research that present the results of NASA programs and include extensive data or theoretical analysis. Includes compilations of significant scientific and technical data and information deemed to be of continuing reference value. NASA counterpart of peer-reviewed formal professional papers but has less stringent limitations on manuscript length and extent of graphic presentations.

- TECHNICAL MEMORANDUM. Scientific and technical findings that are preliminary or of specialized interest, e.g., quick release reports, working papers, and bibliographies that contain minimal annotation. Does not contain extensive analysis.

- CONTRACTOR REPORT. Scientific and technical findings by NASA-sponsored contractors and grantees.
- CONFERENCE PUBLICATION. Collected papers from scientific and technical conferences, symposia, seminars, or other meetings sponsored or cosponsored by NASA.

- SPECIAL PUBLICATION. Scientific, technical, or historical information from NASA programs, projects, and missions, often concerned with subjects having substantial public interest.

- TECHNICAL TRANSLATION. Englishlanguage translations of foreign scientific and technical material pertinent to NASA's mission.

Specialized services also include creating custom thesauri, building customized databases, organizing and publishing research results.

For more information about the NASA STI program, see the following:

- Access the NASA STI program home page at http://www.sti.nasa.gov

- E-mail your question via the Internet to help@ sti.nasa.gov

- Fax your question to the NASA STI Help Desk at $443-757-5803$

- Telephone the NASA STI Help Desk at 443-757-5802

- Write to: NASA Center for AeroSpace Information (CASI) 7115 Standard Drive Hanover, MD 21076-1320 


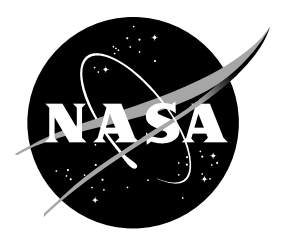

\section{Jet Noise Scaling in Dual Stream Nozzles}

Abbas Khavaran

ASRC Aerospace Corporation, Cleveland, Ohio

James Bridges

Glenn Research Center, Cleveland, Ohio

Prepared for the

16th Aeroacoustics Conference

cosponsored by the American Institute of Aeronautics and Astronautics and the Confederation of European Aerospace Societies

Stockholm, Sweden, June 7-9, 2010

National Aeronautics and

Space Administration

Glenn Research Center

Cleveland, Ohio 44135 


\section{Acknowledgments}

The Fundamental Aeronautics Subsonic Fixed Wing (SFW) and Supersonic Projects (SUP) at NASA supported this work. The authors would like to acknowledge Dr. Milo Dahl, acoustics branch, NASA Glenn Research Center, for his thorough and constructive comments.

This report is a formal draft or working paper, intended to solicit comments and ideas from a technical peer group.

This work was sponsored by the Fundamental Aeronautics Program at the NASA Glenn Research Center.

Level of Review: This material has been technically reviewed by technical management.

Available from

NASA Center for Aerospace Information 7115 Standard Drive

Hanover, MD 21076-1320
National Technical Information Service 5301 Shawnee Road Alexandria, VA 22312

Available electronically at http://gltrs.grc.nasa.gov 


\title{
Jet Noise Scaling in Dual Stream Nozzles
}

\author{
Abbas Khavaran \\ ASRC Aerospace Corporation \\ Cleveland, Ohio 44135 \\ James Bridges \\ National Aeronautics and Space Administration \\ Glenn Research Center \\ Cleveland, Ohio 44135
}

\begin{abstract}
Power spectral laws in dual stream jets are studied by considering such flows a superposition of appropriate single-stream coaxial jets. Noise generation in each mixing region is modeled using spectral power laws developed earlier for single stream jets as a function of jet temperature and observer angle. Similarity arguments indicate that jet noise in dual stream nozzles may be considered as a composite of four single stream jets representing primary/secondary, secondary/ambient, transition, and fully mixed zones. Frequency filter are designed to highlight spectral contribution from each jet. Predictions are provided at an area ratio of 2.0-bypass ratio from 0.80 to 3.40, and are compared with measurements within a wide range of velocity and temperature ratios. These models suggest that the low frequency noise in unheated jets is dominated by the fully mixed region at all velocity ratios, while the high frequency noise is dominated by the secondary when the velocity ratio is larger than 0.80 . Transition and fully mixed jets equally dominate the low frequency noise in heated jets. At velocity ratios less than 0.50 , the high frequency noise from primary/bypass becomes a significant contributing factor similar to that in the secondary/ambient jet.
\end{abstract}

\section{Nomenclature}

$\begin{array}{ll}A & \text { Jet exit area } \\ B & \text { Intercept parameter } \\ c & \text { Sound speed } \\ D & \text { Jet diameter } \\ D_{i} & \text { Inner diameter in the secondary jet } \\ D_{e} & \text { Effective diameter } \\ c_{p} & \text { Specific heat at constant pressure } \\ f, f^{*} & \text { Frequency, characteristic frequency } \\ h, h^{\text {o }} & \text { Static and stagnation enthalpy } \\ m^{\cdot} & \text { Mass flow rate } \\ M & \text { Mach number } \\ n & \text { Velocity power factor } \\ T, T^{\circ} & \text { Static and stagnation temperature } \\ U & \text { Mean axial velocity } \\ \delta & \text { Diameter ratio }\left(D_{i} / D_{p}\right) \\ \gamma & \text { Specific heat ratio } \\ \lambda_{A}, \lambda_{v} & \text { Area and velocity ratio-secondary divided by primary } \\ \lambda_{T} & \text { Static temperature ratio-primary divided by secondary } \\ \theta & \text { Polar angle from inlet axis } \\ \rho & \text { Density }\end{array}$




$\begin{array}{ll}\xi & \text { Normalized frequency }\left(f / f^{*}\right) \\ \eta & \text { Normalized radial distance }\end{array}$

\section{Subscripts}

$\begin{array}{ll}p & \text { Primary jet (core) } \\ s & \text { Secondary jet (bypass) } \\ e & \text { Transition jet } \\ m & \text { Fully mixed jet }\end{array}$

\section{Superscripts}

$\begin{array}{ll}(p) & \text { Primary jet condition } \\ (s) & \text { Secondary jet condition } \\ (m) & \text { Mixed jet condition }\end{array}$

\subsection{Introduction}

Development of robust and high fidelity jet noise prediction models applicable to dual stream flows is of great interest to turbofan engine designers. RANS-based jet noise prediction models that use variants of Lilley's acoustic analogy are computationally intensive, and require dedicated flow solvers to provide input for sources of jet noise in heated flows. Additionally, such methods are difficult to implement in an iterative fashion in conjunction with multi-disciplinary design, analysis, and optimization tools. In an earlier study, an extensive set of high quality jet noise measurements gathered at the AeroAcoustic Propulsion Laboratory (AAPL) at the NASA Glenn Research Center (Refs. 1, 2, and 3) was used to develop intensity-scaling laws for the jet mixing noise in single stream jets. The result is a very robust code, labeled sJet (for Single stream Jets), that implements the intensity laws and scales the jet noise power spectral density from a limited bank of subsonic conditions to a user specified set of conditions that include supersonic jets (Refs. 4 and 5). It is well known that supersonic jets at imperfectly expanded pressures emit two distinct noise components, i.e., the jet mixing noise and the broadband shock associated noise (BBSN). The scaling laws were additionally extended to the broadband shock associated noise (Ref. 5) when the jet mixing noise was subtracted from the total spectrum in order to isolate the BBSN component. Subsequently a semi-empirical model was proposed for this noise component that used a known peak-amplitude and frequency, combined with appropriate spectral attenuation on either side from the peak.

The present work attempts to develop a similar intensity-scaling methodology for jet mixing noise in turbofan engines. Such an effort represents a formidable task due to the order of increase in parameters involved compared to those in single stream flows. In addition to the gas dynamic parameters, the geometrical details of a dual stream nozzle influence the generation of both mixing noise and the broadband shock noise. From an aerodynamic point of view, a detailed study of the mean flow and turbulence should be emphasized as a guide in understating the noise generation mechanism in such flows. This is accomplished by holding one jet at a fixed operating condition while incrementally changing the second jet. Naturally, any noise-modeling recipe is expected to asymptotically approach a single stream jet when either the primary or the secondary dominates the jet exhaust.

Stone et al. (Refs. 6 and 7) studied jet noise from co-annular nozzles with and without a center-body plug. Using an extensive data set at nozzle bypass ratios from 5 to 14 they proceeded with component extraction and proposed semi-empirical correlations for what they considered as important noise components. Stone modeled his single-stream round jet predictions on Lighthill's general scaling law in cold jets, and added some empiricism for effects such as refraction and temperature effect. These models are currently coded into the NASA Aircraft Noise Prediction Program (ANOPP) and provide a first estimate of jet noise from turbofan engines. 
Fisher et al. (Ref. 8) pioneered a scaling approach for jet noise in dual stream flows from a fluid mechanics perspective of such streams. In the light of velocity and turbulence measurements, they divided a coaxial dual stream jet into several noise-generating segments. Although these noise-producing regions beard some resemblance to those suggested by Stone, they differed in their noise modeling details. Later, Fisher extended the model to heated jets (Ref. 9) with a dipole-equivalent correction term that represented the temperature effect in the transition jet. These studies were limited in their scope and applicability of the velocity, area, and temperature ratio between the two streams, and did not examine important geometrical details such as a recessed secondary that is typical of the present turbofan engine designs.

The objective of the present study is to construct a composite spectrum for the jet mixing noise by considering a dual stream jet as a superposition of un-correlated single-stream equivalent jets. Each single stream jet is regarded as a component in the context of its spectral contribution to the total noise. Component noise is determined per velocity scaling laws. These laws state that turbulent mixing noise in a single stream jet scales with some power of the mean exit velocity, referred to as the velocity exponent or velocity power factor $n$. Since velocity exponents vary with jet temperature (Ref. 5), we expect that a composite spectrum should equally hold at different temperatures without additional adjustments. Each component noise undergoes a spectral filtering that reflects pertinent turbulence scales in that region of the jet. Filter functions (high- or low-pass filters) are determined by a combination of physical reasoning and iteration within the bounds of the available jet parameters.

The single-stream jet noise prediction model adopted for this work is briefly reviewed in Section 2.0, and is followed by a review of the similarity arguments in dual stream subsonic jets. These discussions lay grounds for component splitting and spectral filtering in Section 3.0. Spectral predictions in dual stream jets are presented in Section 4.0 at area ratio of 2, which include both unheated and heated primary flows (stagnation temperature ratio of 1.0 to 2.67), and at nozzle bypass ratios from 0.80 to 3.40 . A summary of the results and direction for the follow-on research is given in Section 5.0.

\subsection{Method of Approach}

We start with the velocity power laws for the turbulent mixing noise in shock-free single-stream jets. In a previous study, an extensive matrix of jet noise spectral data acquired from the Small Hot Jet Acoustic Rig (SHJAR) (Refs. 1, 2, and 3) at the NASA Glenn Research Center was used to develop velocity power laws in single stream jets. Power spectral density $P S D$ for the turbulent mixing noise was shown to scale from one jet velocity to the next, on a Strouhal frequency basis as (Ref. 4)

$$
\operatorname{PSD}\left(\theta, T_{2}^{o}, U_{2}\right)-P S D\left(\theta, T_{1}^{o}, U_{1}\right)=10 \log \left(U_{2} / U_{1}\right)^{n\left(\theta, T_{2}^{o}\right)}+\left(B\left(\theta, T_{2}^{o}\right)-B\left(\theta, T_{1}^{o}\right)\right) .
$$

Parameters $n$ and $B$ are referred to as the velocity power factor and the intercept parameter. These parameters were determined from SHJAR measurements as a function of angle and jet temperature as seen in Figure 1.

When jets become supersonic, the basic shape of the spectrum at small aft angles changes with jet velocity. This is due to the presence of the instability-related noise that increasingly dominates the aft angles at supersonic speeds. The jet mixing noise along sideline and forward angles would still scale according to the power law (1) provided that $U$ is replaced with a fully expanded jet velocity, and an additional term $10 \log \left(A_{j 2} / A_{j 1}\right)$ is added to the right-hand-side of Equation (1)-where $A_{j}$ is the fully expanded jet area. The total noise in supersonic shock-containing jets includes an additional component attributed to the broadband shock associated noise. The intensity of BBSN depends on the difference between the fully expanded jet Mach number and the design Mach number. Similar to the jet mixing noise, intensity scaling of shock noise requires two parameters $m\left(\theta, T^{\circ}\right)$ and $B_{\text {shock }}\left(\theta, T^{\circ}\right)$ referred to as intensity exponent and the intercept parameter (see Figure 2).

When jet noise in considered as a superposition of multiple equivalent single-stream jets, Equation (1) is applicable to each jet through parameters $U, T$ and $D$ that best represent that component stream. 

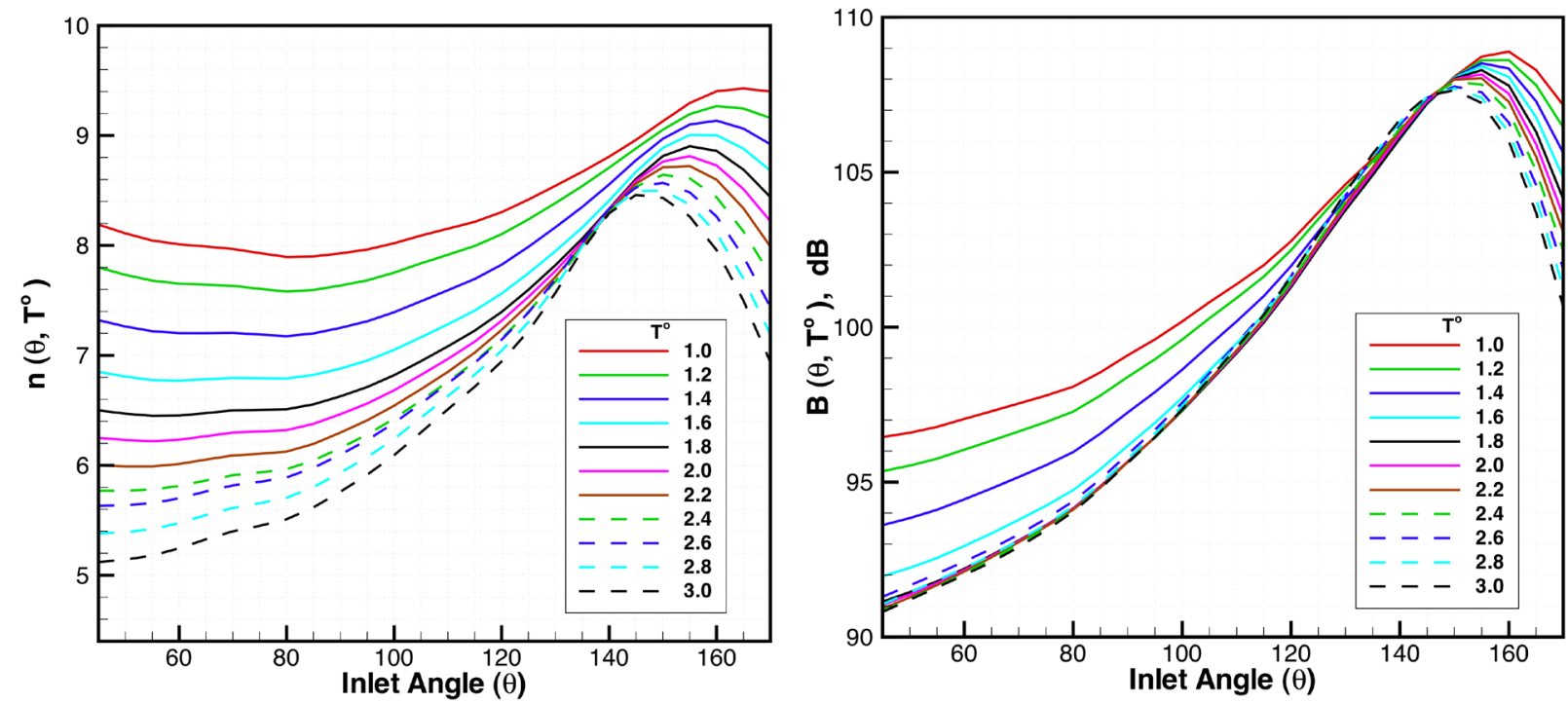

Figure 1.-Velocity power exponent $n$ and intercept parameter $B$ as a function of angle and stagnation temperature ratio in single stream jets (parameter $B$ is evaluated as lossless dB at 100D Arc).
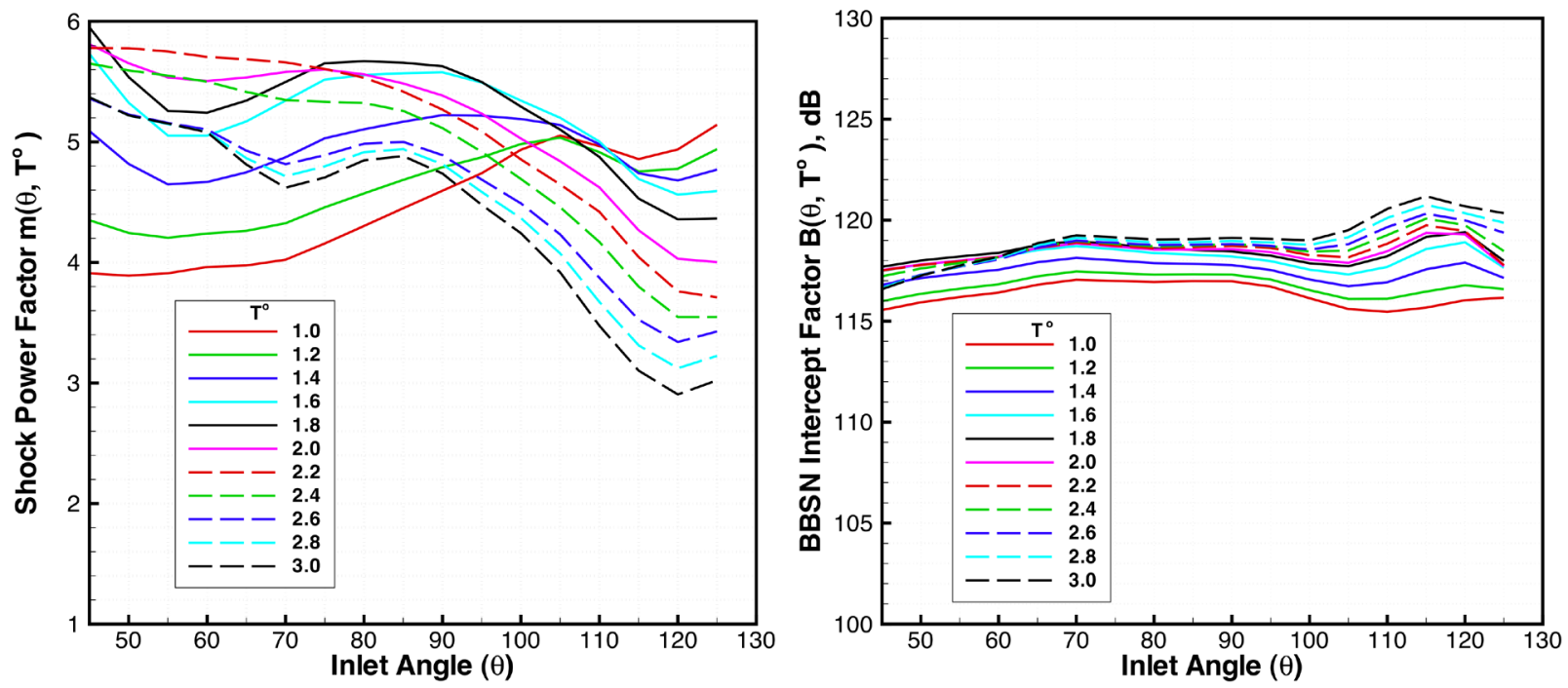

Figure 2.-Shock noise intensity exponent $m$ and intercept factor $B$ in single stream convergent nozzles (parameter $B$ is evaluated as lossless $\mathrm{dB}$ at $100 D \mathrm{Arc}$ ).

\subsection{Fully Mixed Jet}

The similarity arguments discussed in the next section conclude that a dual stream jet could be divided into three regions (four zones) as sketched in Figure 3. The initial mixing region consists of two zones that reflect the mixing between primary/secondary and secondary/ambient streams. A transition region where the two mixing layers merge, and subsequently a fully mixed region further downstream follow this. Noise generation from each of the four zones is addressed through an equivalent single stream jet with three parameters $U, T$ and $D$. In this section we discuss these parameters as related to the fully mixed region of the jet. 


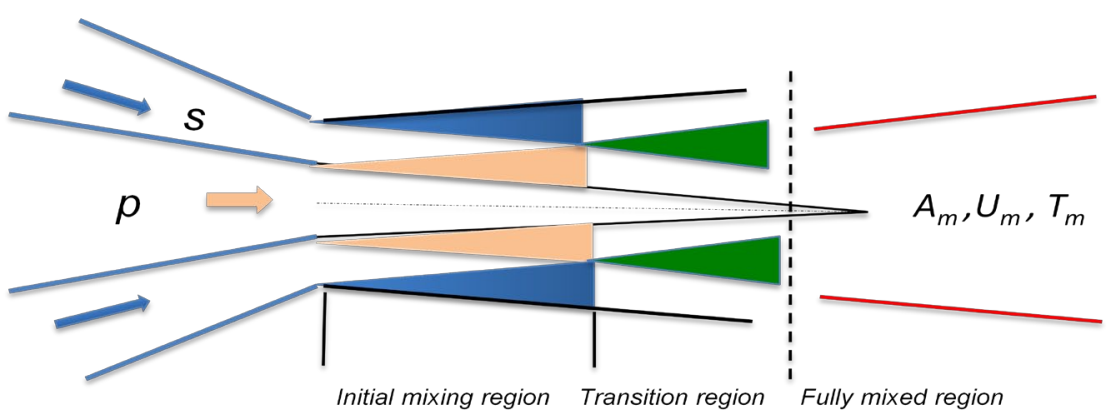

Figure 3.-Schematic of a dual stream jet showing mixing zones primary/bypass, bypass/ambient, the transition, and the fully mixed region.

Let the primary (or core), the secondary (or bypass), and the fully mixed streams in a dual stream jet be identified by subscripts $p, s$ and $m$ respectively. The one-dimensional conservation equations plus the equation of state (assuming a constant static pressure) are written as

$$
\begin{array}{ll}
\rho_{p} U_{p} A_{p}+\rho_{s} U_{s} A_{s}=\rho_{m} U_{m} A_{m} & \text { (mass) } \\
\rho_{p} U_{p}^{2} A_{p}+\rho_{s} U_{s}^{2} A_{s}=\rho_{m} U_{m}^{2} A_{m} & \text { (momentum) } \\
\rho_{p} U_{p} h_{p}^{o} A_{p}+\rho_{s} U_{s} h_{s}^{o} A_{s}=\rho_{m} U_{m} h_{m}^{o} A_{m} & \text { (energy) } \\
\rho_{p} T_{p}=\rho_{s} T_{s}=\rho_{m} T_{m} & \text { (state) }
\end{array}
$$

where stagnation enthalpy is $h^{o}=c_{p} T+U^{2} / 2=c_{p} T^{o}$, and $c_{p}=\gamma R /(\gamma-1)$. For simplicity, we use the following definitions

$$
\begin{aligned}
& \lambda_{V} \equiv \frac{U_{s}}{U_{p}}, \quad \lambda_{A} \equiv \frac{A_{s}}{A_{p}}, \\
& \lambda_{T} \equiv \frac{T_{p}}{T_{s}}=\frac{\rho_{s}}{\rho_{p}}, \quad \lambda_{T^{o}} \equiv \frac{T_{p}^{o}}{T_{s}^{o}} .
\end{aligned}
$$

The fully mixed jet conditions are solved from eqns. (2) and (3) as

$$
\begin{aligned}
& \frac{U_{m}}{U_{p}}=\frac{1+\lambda_{V}^{2} \lambda_{A} \lambda_{T}}{1+\lambda_{V} \lambda_{A} \lambda_{T}}, \\
& \frac{T_{m}^{o}}{T_{p}^{o}}=\frac{1+\lambda_{V} \lambda_{A} \lambda_{T} / \lambda_{T^{o}}}{1+\lambda_{V} \lambda_{A} \lambda_{T}}, \\
& \frac{A_{m}}{A_{p}}=\frac{D_{m}^{2}}{D_{p}^{2}}=\left(1+\lambda_{V} \lambda_{A} \lambda_{T}\right)\left(\frac{\rho_{p}}{\rho_{m}}\right) /\left(\frac{U_{m}}{U_{p}}\right), \\
& \frac{T_{m}}{T_{p}}=\frac{\rho_{p}}{\rho_{m}}=\frac{T_{m}^{o}}{T_{p}^{o}}+\frac{1}{2 c_{p}^{(p)}} \frac{U_{p}^{2}}{T_{p}}\left(\frac{T_{m}^{o}}{T_{p}^{o}}-\frac{c_{p}^{(p)}}{c_{p}^{(m)}} \frac{U_{m}^{2}}{U_{p}^{2}}\right) .
\end{aligned}
$$

The specific heat ratios $\gamma^{(p)}$ and $\gamma^{(s)}$ in the primary and the secondary are evaluated at their respective temperatures, and are used to evaluate the mixed specific heat ratio $\gamma^{(m)}=\left(\gamma^{(p)} m_{p}^{\cdot}+\gamma^{(s)} m_{s}^{\cdot}\right) /\left(m_{p}^{*}+m_{s}^{*}\right)$, where $m^{\bullet}$ is the mass flow rate. 


\subsection{Similarity in Subsonic Coaxial Jets}

Dual stream jets at subsonic conditions have been examined experimentally by a number of investigators. Ideas presented here, and similarly proposed by Fisher et al. (Ref. 8), are founded on measurements of Ko and Kwan (Ref. 10) obtained at low subsonic conditions. They tested a 0.18 -Mach number unheated primary jet $U_{p}=197$ fps combined with a secondary jet at velocity ratios of $U_{s} / U_{p}=0.70,0.50,0.30$. Using an appropriately defined non-dimensional radial distance, they identified four distinct zones based on similarity arguments (see Figure 3). The initial mixing region consists of two zones, and ends near the termination point of the secondary potential core. Similarity of the velocity profile could be shown for both the primary and the secondary jets when the local mean velocity ratio $\left(U-U_{s}\right) /\left(U_{p}-U_{s}\right)$ is plotted versus normalized radial distance $\eta_{p}=\left(y-y_{0.5}\right) /\left(y_{0.9}-y_{0.1}\right)$ for the primary, and $U / U_{s}$ versus $\eta_{s}=\left(y-D_{s} / 2\right) / x$ for the secondary flow (see Abramovich, Ref. 11). The second region, identified as the transition region starts at the end of the secondary potential core. This is the region where the two jets mix. The potential core of the primary flow could persist through the transition region and stretch farther into the subsequent fully mixed region depending on the velocity ratio of the two streams. The transition region is highlighted mainly by an absence of any similarity velocity profile.

Following this region, similarity of the local mean velocity is displayed again in the fourth or the fully mixed region. Eldred et al. (Ref. 12) defined a radial parameter $\eta_{e}=\left(y-D_{e} / 2\right) / x_{e}$ to show similarity for mean velocity ratio $U / U_{p}$ in this region. The virtual origin for this jet is $x_{e}=x-\Delta x$, where shift $\Delta x$ is measured relative to the primary exit, and depends on the secondary-to-primary velocity ratio $\lambda_{V}$. The effective diameter $D_{e}$ (see Eq. (10)) is defined for an equivalent jet of velocity $U_{p}$ having an identical thrust as that of the dual stream jet. In the following section, we define the fully mixed diameter $D_{m}$ for a dual stream nozzle. Since diameter ratio $D_{e} / D_{m}$ is a fixed number, the similarity of local mean velocity $U / U_{p}$ should equivalently hold relative to the radial parameter $\eta_{m}=\left(y-D_{m} / 2\right) / x_{m}$ in the fully mixed region.

Of primary interest in any jet noise prediction algorithm is the source strength, i.e., the turbulence intensity distribution. Figure 4, reproduced from data of (Ref. 10), shows turbulence intensity as a percentage of the primary jet velocity at selective stream-wise locations from near the exit at $0.5 D_{p}$ to $8 D_{p}$.

The peak turbulence in the fully mixed region is nearly 11.75 percent of the primary velocity as seen in Figure 4. Using test condition parameters $\lambda_{V}=0.70, \lambda_{T}=1.0$, and $\lambda_{A}=2.67$ in the conservation equations, the mixed flow parameters are evaluated as $D_{m} / D_{p}=1.89$ and $U_{m} / U_{p}=0.80$. Therefore the peak turbulence as a percentage of the fully mixed velocity is $\sim 14.7$ percent, similar to a single stream jet. This provides an impetus to treat this region as a single stream jet for noise considerations - although an appropriate filter would be required to tone down its high frequency content.

In the transition zone $\left(x / D_{p} \simeq 6.0\right)$, the peak turbulence is typified by $\sim 7$ percent (at $y / D_{p} \simeq 0.6$ ) relative to primary jet velocity, or nearly 60 percent of the peak turbulence if this zone were to be treated as a single stream jet at the primary jet conditions $\left(U_{p}, T_{p}\right)$. For this reason the turbulence intensity level is attenuated by a factor of 0.60 and the region is treated as a single stream jet with an effective diameter $D_{\mathrm{e}}$ resulting in a similar thrust as the dual stream jet. Additionally, a high frequency filter will be introduced to moderate its high frequency noise so that the combined spectra from the transition and the initial mixing regions agree with measurements at high frequency.

We now turn our attention to the initial mixing region in Figure 3. As for the secondary jet, measurements of Ko and Kwan (Ref. 10, Figure 6) show similarity of turbulence intensity $u^{\prime} / U_{s}$ versus radial parameter $\eta_{s}$ at each velocity ratio $\lambda_{V}$ in the secondary mixing region. As $\lambda_{V}$ increases, the turbulence ratio approaches $\sim 14$ percent, similar to a single stream jet. Deviations from similarity appear mostly in the inner part of the mixing region $\left(\eta_{s}<0\right)$, while the outer part $\eta_{s}<0$ conforms closely with the single stream jet similarity at all $\lambda_{V}$. Consequently, it seems appropriate to treat this mixing region as a single stream jet at the secondary conditions, and with a suitable filter to tone down its low frequency content - as this noise component is due primarily to the large vortices in the fully mixed jet. Further, 


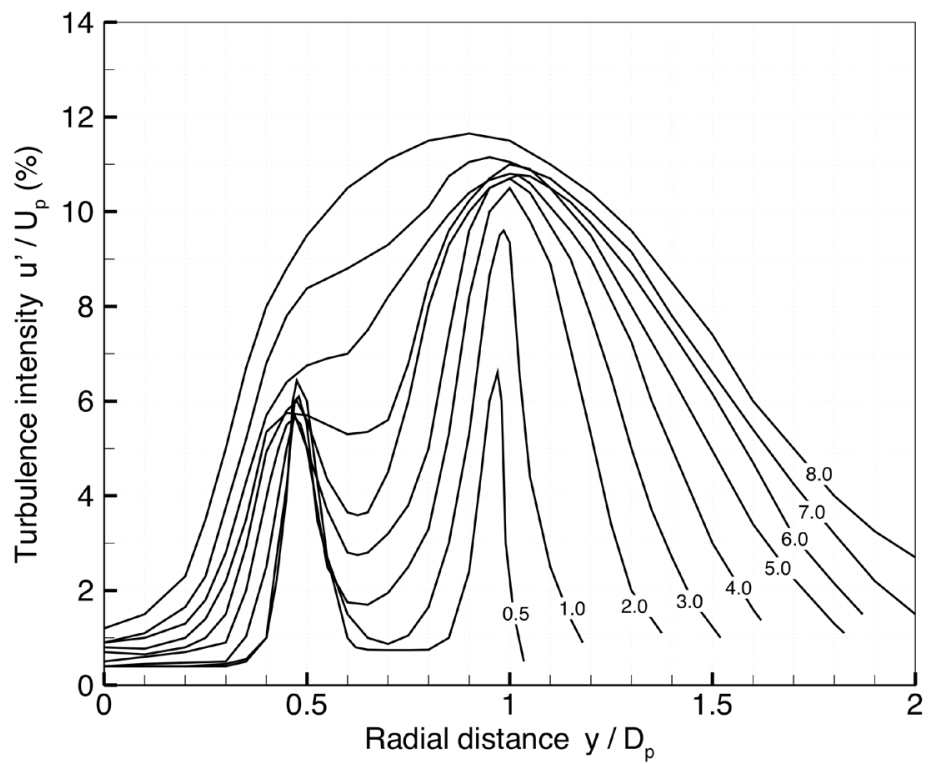

Figure 4.-Radial distribution of turbulence intensity in a dual stream jet at $\lambda_{v}=0.70$, and at axial locations, $x / D_{p}=0.50,1.0$, 2.0, 3.0, 4.0, 5.0, 6.0, 7.0, 8.0 (Ref. 10).

the filter could also be tailored to represent the effect of the lip thickness (i.e., the radial separation between the secondary nozzle inner radius and the primary lip).

Next, we consider the primary and secondary stream shear layer within the initial mixing region. This mixing zone resembles that of a jet discharging into a moving ambient with velocity $U_{s}$. As shown in (Ref. 10, Figure 7), similarity is observed for turbulence intensity $u^{\prime} /\left(U_{p}-U_{s}\right)$ versus normalized radial distance $\eta_{p}$. Unlike the secondary shear layer, the slight deviation from single stream jet similarity is measured on the positive side of $\eta_{p}$. Due to reduced shear, this mixing layer contributes little to the overall jet noise spectra, however, from a modeling standpoint, it should be compatible with the limiting case as $\lambda_{V} \rightarrow 0$ so we can recover the single stream jet noise spectra.

In the next section, we discuss the frequency filters designed for each noise-generating region so that in combination they can afford a dual stream jet noise spectrum at a range of angles and operating conditions. This includes both isothermal and heated flows and jets with an inverted velocity profiles (i.e., $\left.\lambda_{V}>1\right)$.

\subsection{Frequency Filters}

The exhaust geometry in a dual stream coaxial jet is sketched in Figure 5. In general, the inner diameter of the outer nozzle is larger than the diameter of the inner stream due to the wall thickness or a recessed secondary, and/or other geometrical considerations. The flow area ratio can be expressed as

$$
\lambda_{A}=\frac{D_{s}^{2}}{D_{p}^{2}}-\delta^{2}, \quad \delta \equiv \frac{D_{i}}{D_{p}}
$$

When the two streams discharge at the same axial location the wall thickness should be kept to a minimum (i.e., $\delta \rightarrow 1$ ) to avoid a wake and discontinuity in the nozzle profile at the exit that could lead to discrete tones.

The filters defined subsequently each depend on a cut-off frequency and are designed to tone down either the high- or the low-frequency spectral density $(\mathrm{dB})$ as a function of frequency. 


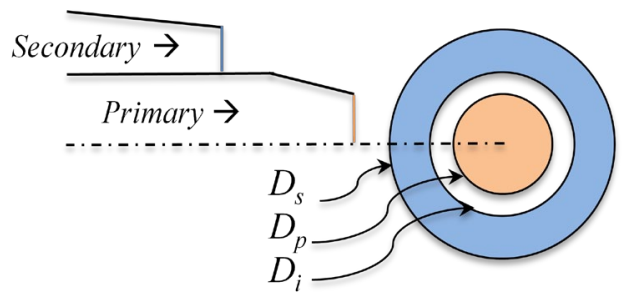

Figure 5.-Dual stream coaxial jets.

Let $f^{*}$ denote a characteristic frequency (defined shortly), and

$$
\xi \equiv m \frac{f}{f^{*}}, \quad m=2 .
$$

Consider two filter functions as

$$
\begin{aligned}
& F_{1}(\xi)=\left(1+\xi+\frac{\xi^{2}}{25}+\frac{\xi^{3}}{125}+\frac{\xi^{4}}{250}\right) e^{-\xi}, \\
& F_{2}(\xi)=\left(1+\xi+\frac{\xi^{2}}{2}+\frac{\xi^{3}}{6}\right) e^{-\xi} .
\end{aligned}
$$

Each of the four noise producing zones undergoes a filtering that reflects the predominant noisegenerating scales in that zone. The functions defined in Equation (7) work as low- and/or high-pass filters, and are determined by iteration and comparison of the predicted spectra with measurements.

\subsection{Fully Mixed Region}

This jet is defined as a single stream jet at $U_{m}, T_{m}$, and $D_{m}$. According to the conservation Equations (4), the fully mixed diameter ratio $D_{m} / D_{p}$ depends on the secondary geometry through area ratio $\lambda_{A}$. Since the secondary jet diameter is uniquely defined through three geometrical parameters according to Equation (5), the characteristic frequency $f^{*}$ in the fully mixed region should additionally depend on parameter $\delta$. We introduce a low-pass filter for this noise-generating region as

$$
f^{*}=\left(\frac{1}{\delta} \frac{U_{m}}{D_{m}}\right), \quad \text { Filter }(f)=10 \log _{10}\left(F_{1}(\xi)\right) .
$$

At a fixed $\lambda_{A}$, a larger $\delta$ adds to the secondary jet diameter, which in turn enhances the fully mixed diameter and decrease its characteristic frequency.

\subsection{The Secondary Jet}

This jet is defined through the secondary jet parameters $U_{s}, T_{s}$, and $D_{s}$, and is expected to contribute to the high frequency noise. The required high-pass filter should be compatible with that in the fully mixed region to accommodate the limiting case when the primary jet becomes relatively weak. In that case, the fully mixed jet and the secondary are identical and the two filters should recover a single jet at the secondary conditions. Parameter $\delta$ best fits the characteristic frequency in the secondary jet as

$$
f^{*}=\delta^{3}\left(\frac{U_{S}}{D_{S}}\right), \quad \text { Filter }(f)=10 \log _{10}\left(1-F_{1}(\xi)\right)
$$




\subsection{Transition Jet}

Due to the lack of an intrinsic similarity within the region, this jet is relatively more ambiguous and requires a more delicate treatment. Per discussions presented earlier, it is best defined as single stream jet at $U_{p}, T_{p}$, and $D_{e}$. The effective diameter is calculated per equal thrust to that of the dual stream jets

$$
\frac{D_{e}^{2}}{D_{p}^{2}}=1+\lambda_{A} \lambda_{T} \lambda_{V}^{2} .
$$

Since the maximum turbulence intensity is of the order of 60 percent of the primary jet velocity, the noise level needs to be attenuated accordingly by this percentage - raised to some exponent. A proper exponent $(7 / 2)$ is derived from physics-based jet noise modeling (Ref. 13) that scales jet mixing noise versus turbulence intensity. Additionally, a low-pass filter is used at an appropriate characteristic frequency

$$
f^{*}=\frac{U_{p}}{D_{e}}, \quad \text { Filter }(f)=10 \log _{10}(0.60)^{7 / 2}+10 \log _{10}\left(\frac{F_{2}\left(\xi /\left(3 / \lambda_{A}\right)^{3}\right)}{F_{2}\left(\hat{m} /\left(3 / \lambda_{A}\right)^{3}\right)}\right)
$$

where $\hat{m}=\operatorname{Min}(m, \xi)$. The filter, denoted as the second term on the RHS of Equation (11), works more effectively as $\lambda_{A}$ increases. Parameter $\lambda_{A}$ in (11) is replaced with its limits at $\lambda_{A}>3$ or $\lambda_{A}<1$ such that $1.0 \leq \lambda_{A} \leq 3.0$. When combined with the high frequency noise from the secondary jet, these two noise components should be required to match the total high frequency noise in a dual stream nozzle.

\subsection{Primary Jet}

This jet is defined through parameters $U_{p}, T_{p}$, and $D_{p}$, and is considered subject to a flight speed of $U_{\infty}=U_{s}$. The required high-pass filter is bound by the limiting requirements at $U_{s} \rightarrow 0$.

$$
f^{*}=\left|U_{p}-U_{s}\right| / D_{p}, \quad \operatorname{Filter}(f)=10 \log _{10}\left(1-F_{1}(\xi)\right)
$$

When the secondary jet is relatively insignificant, the fully mixed jet and the primary become identical. The two jets subject to the proposed filters recover the primary jet, as expected. The only caveat is that a virtual transition flow is also in the pictures, and is identical to the primary jet. The filter function in Equation (11) suggests an additional contribution from this jet to the total noise spectral density

$$
10 \log _{10}\left(1+0.60^{7 / 2}\right)=0.67 \mathrm{~dB}
$$

In the next section, the proposed models are examined at a number of conditions and the jet noise spectral density in dual stream nozzles is evaluated as a superposition of the four uncorrelated spectra subject to their respective filters.

\subsection{Numerical Results}

Turbulent mixing noise from the four aforementioned zones are combined to form a composite spectrum as follows:

i. Appropriate equivalent single jet parameters $U, T$ and $D$ are supplied to the $S J e t$ code that predicts the turbulent mixing noise in single-stream jets according to the velocity power laws. Four predicted component noise tables are stored as 1/3-Octave lossless spectra. 
ii. Each component noise undergoes a low- or high-pass filter.

iii. A composite spectrum is formed as:

$$
10^{S P L / 10}=10^{(S P L / 10)_{\text {primary }}}+10^{(S P L / 10)_{\text {secondary }}}+10^{(S P L / 10)_{\text {transition }}}+10^{(S P L / 10)_{\text {fully-mixed }}} .
$$

In addition to the jet mixing noise, broadband shock associated noise could be a significant factor if either of the two streams is imperfectly expanded (Ref. 14).

Next acoustic measurements are compared with predictions at a range of temperatures and subsonic pressure ratios in the two streams.

\subsection{Coaxial Jet Noise Data (Fisher et al.)}

These measurements were reported by Fisher et al. (Refs. 8, 9, and 15) and were carried out in the large anechoic chamber at the Defense Research Agency (DRA) in the United Kingdom to investigate flow/noise characteristics of coaxial jets. The nozzles consist of co-planar primary and secondary jets at $D_{p}=1.307$ in., $D_{s}=2.291 \mathrm{in}$. and $\lambda_{A}=2.0$, and with a measured discharge coefficient close to unity. Details of the experimental setup are provided in (Ref. 8). Noise data presented here have been scanned from the publicly available reports and the AIAA references (Refs. 8, 9, and 15).

A sample of 11 set points is listed in Table 1, each identified by a run number that will be used in the presentation. All cases are subsonic, with a maximum nozzle pressure ratio of 1.79 at Run no. P038. The bypass ratio varies from 1.0 (Run no. P038) to 3.38 (Run no. P043).

$$
B P R=m_{s}^{\cdot} / m_{p}^{\cdot}=\lambda_{V} \lambda_{A} \lambda_{T}
$$

Spectral data at several run conditions were provided at $90^{\circ}$ only, while most were reported at three inlet angles of $40^{\circ}, 90^{\circ}$ and $140^{\circ}$. The stagnation temperature ratio in the primary stream is 1.0 at each of the first eight measurement points, and is subsequently increased to 2.0 and 2.67 at the last three set points. The secondary flow remains unheated throughout.

Predictions are presented as lossless, 1/3-Octave sound pressure level (SPL) on a 6 m (236.2 in.) arc.

\begin{tabular}{|c|c|c|c|c|c|c|c|c|c|c|}
\hline \multirow{2}{*}{$\begin{array}{c}\text { Run } \\
\text { no. }\end{array}$} & \multicolumn{4}{|c|}{ Primary } & \multicolumn{4}{|c|}{ Secondary } & \multirow{2}{*}{$\lambda_{V}$} & \multirow[t]{2}{*}{$\lambda_{T}$} \\
\hline & $N P R$ & $T^{O}-R$ & $U-f p s$ & $M$ & $N P R$ & $T^{o}-R$ & $U-f p s$ & $M$ & & \\
\hline P018 & 1.241 & 540.0 & 623.2 & 0.56 & 1.570 & 540.0 & 885.6 & 0.83 & 1.42 & 1.07 \\
\hline P019 & 1.318 & 540.0 & 701.2 & 0.64 & 1.117 & 540.0 & 448.7 & 0.40 & 0.64 & 1.00 \\
\hline P023 & 1.190 & 543.0 & 561.5 & 0.50 & 1.186 & 543.1 & 557.6 & 0.50 & 0.99 & 1.00 \\
\hline P027 & 1.244 & 541.8 & 626.8 & 0.57 & 1.186 & 542.5 & 557.6 & 0.50 & 0.89 & 0.98 \\
\hline P028 & 1.325 & 541.6 & 708.5 & 0.64 & 1.186 & 542.3 & 557.6 & 0.50 & 0.79 & 0.97 \\
\hline P032 & 1.424 & 543.2 & 791.8 & 0.73 & 1.186 & 543.6 & 557.6 & 0.50 & 0.70 & 0.95 \\
\hline P035 & 1.570 & 528.8 & 876.4 & 0.83 & 1.192 & 528.7 & 557.6 & 0.50 & 0.63 & 0.93 \\
\hline P038 & 1.791 & 532.6 & 990.2 & 0.95 & 1.191 & 532.6 & 557.6 & 050 & 0.56 & 0.89 \\
\hline P040 & 1.146 & 1080.0 & 705.2 & 0.45 & 1.187 & 540.0 & 557.6 & 0.50 & 0.79 & 2.02 \\
\hline P042 & 1.233 & 1080.0 & 869.2 & 0.56 & 1.180 & 540.0 & 547.6 & 0.49 & 0.63 & 1.98 \\
\hline P043 & 1.169 & 1440.0 & 869.2 & 0.48 & 1.180 & 540.0 & 557.6 & 0.49 & 0.63 & 2.68 \\
\hline
\end{tabular}

TABLE 1.-COANNULAR NOZZLE TEST CONDITIONS (REF. 9), $\lambda_{A}=2.0$

Jet noise prediction and comparisons with measurements at set point conditions of Table 1 are presented in Figure 6 to Figure 16.

Several conclusions are drawn from these predictions:

1. Lowest velocity ratio (i.e., $\lambda_{v}=0.56$ at Run no. P038), high-frequency noise in the primary is comparable to that in the secondary/ambient. 
2. In jets with an unheated primary, a fully mixed jet dominates the low-frequency noise at all conditions. Addition of heat to the primary jet results in the enhancement of low frequency noise in the transition region.

3. The high frequency noise is completely dominated by the secondary jet when velocity ratio exceeds 0.60 .

4. Transition jet dominates the mid-frequency span in most cases. At a constant primary velocity, this jet makes a stronger contribution as the velocity ratio is lowered.

5. At the high velocity ratio $\lambda_{v}>1$, the secondary jet completely dominates the mid- to high-frequency noise. The fully mixed jet determines the low-frequency noise as before (Figure 6 and Figure 8).

6. Increasing the secondary jet speed at a constant primary jet velocity enhances the low-frequency contribution from the fully mixed region.

These results required no special treatment in heated jets versus unheated jets. The basic building block of the prediction methodology, i.e., single stream jet noise model, accounts for temperature variations of both velocity exponent $n\left(\theta, T^{\circ}\right)$ and the intercept parameter $B\left(\theta, T^{\circ}\right)$ according to Figure 1 .

As the secondary-to-primary velocity ratio is lowered to below 0.50 , the high-frequency noise from primary-bypass shear layer dominates the same from other noise generating regions, and dictates the high-frequency noise in a dual-stream jet. This is presented at conditions of Table 2 at a velocity ratio of $\lambda_{v}=0.45$ at a bypass ratio of $B P R=0.78$. Spectral predictions are shown in Figure 17 at two angles of $60^{\circ}$ and $90^{\circ}$. Unfortunately no measurements were available for comparison at this operating condition.

TABLE 2.-COANNULAR NOZZLE CONDITIONS AT $\lambda_{A}=2.0$

\begin{tabular}{|c|c|c|c|c|c|c|c|c|c|c|}
\hline \multirow{2}{*}{$\begin{array}{c}\text { Run } \\
\text { no. }\end{array}$} & \multicolumn{4}{|c|}{ Primary } & \multicolumn{4}{|c|}{ Secondary } & \multirow[t]{2}{*}{$\lambda_{V}$} & \multirow[t]{2}{*}{$\lambda_{T}$} \\
\hline & $N P R$ & $T^{O}-R$ & $U-f p s$ & $M$ & NPR & $T^{O}-R$ & $U-f p s$ & $M$ & & \\
\hline P001 & 1.791 & 540.0 & 997.5 & 0.95 & 1.117 & 540.0 & 448.8 & 0.40 & 0.45 & 0.87 \\
\hline
\end{tabular}
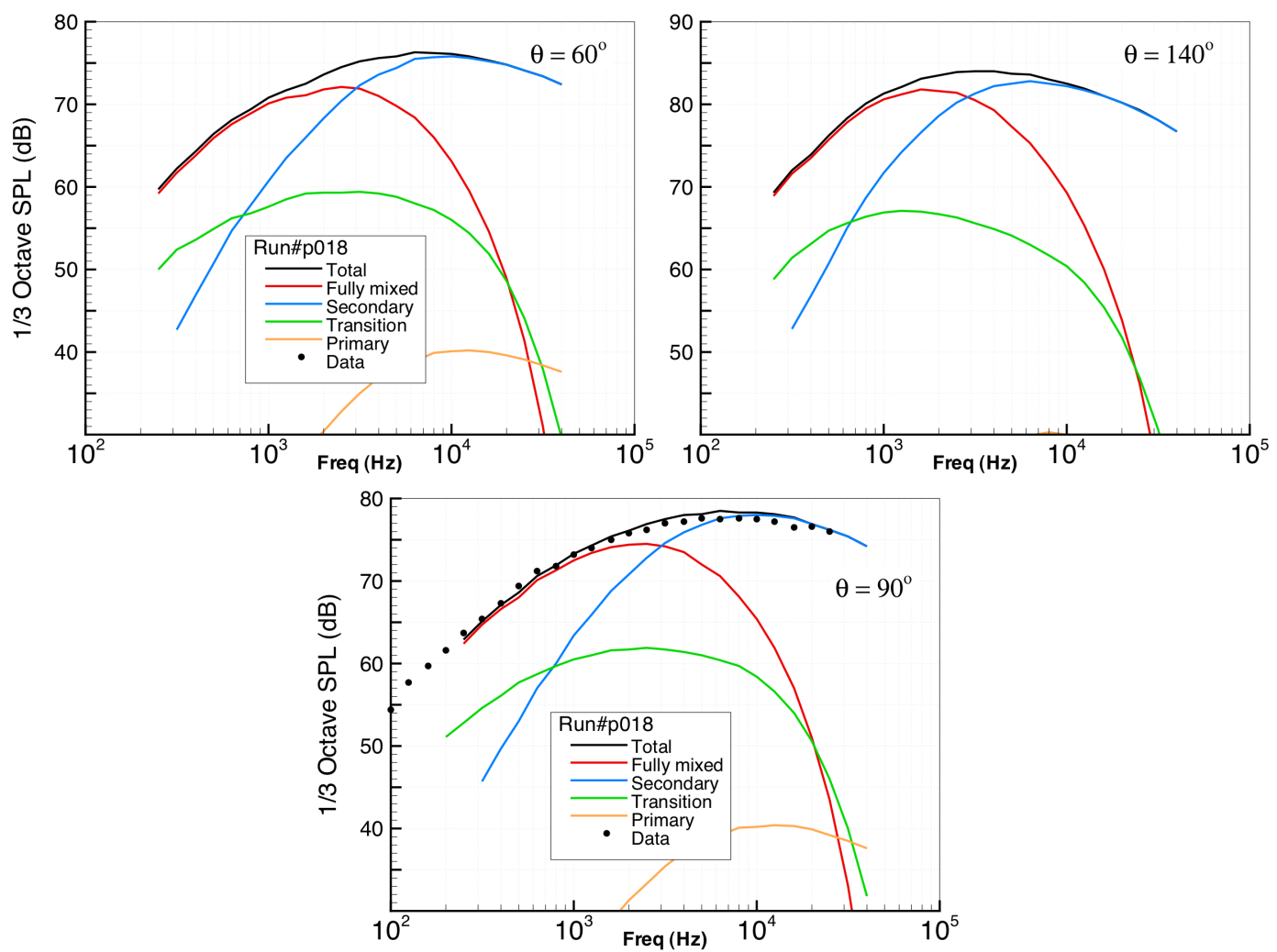

Figure 6.- Jet noise spectrum in dual stream unheated jets at $60^{\circ}, 90^{\circ}$ and $140^{\circ}$ (Run no. P018, Table 1) $T_{p}^{o} / T_{\infty}=1.0, \lambda_{v}=1.42, U_{p}=623.2 \mathrm{fps}$. 

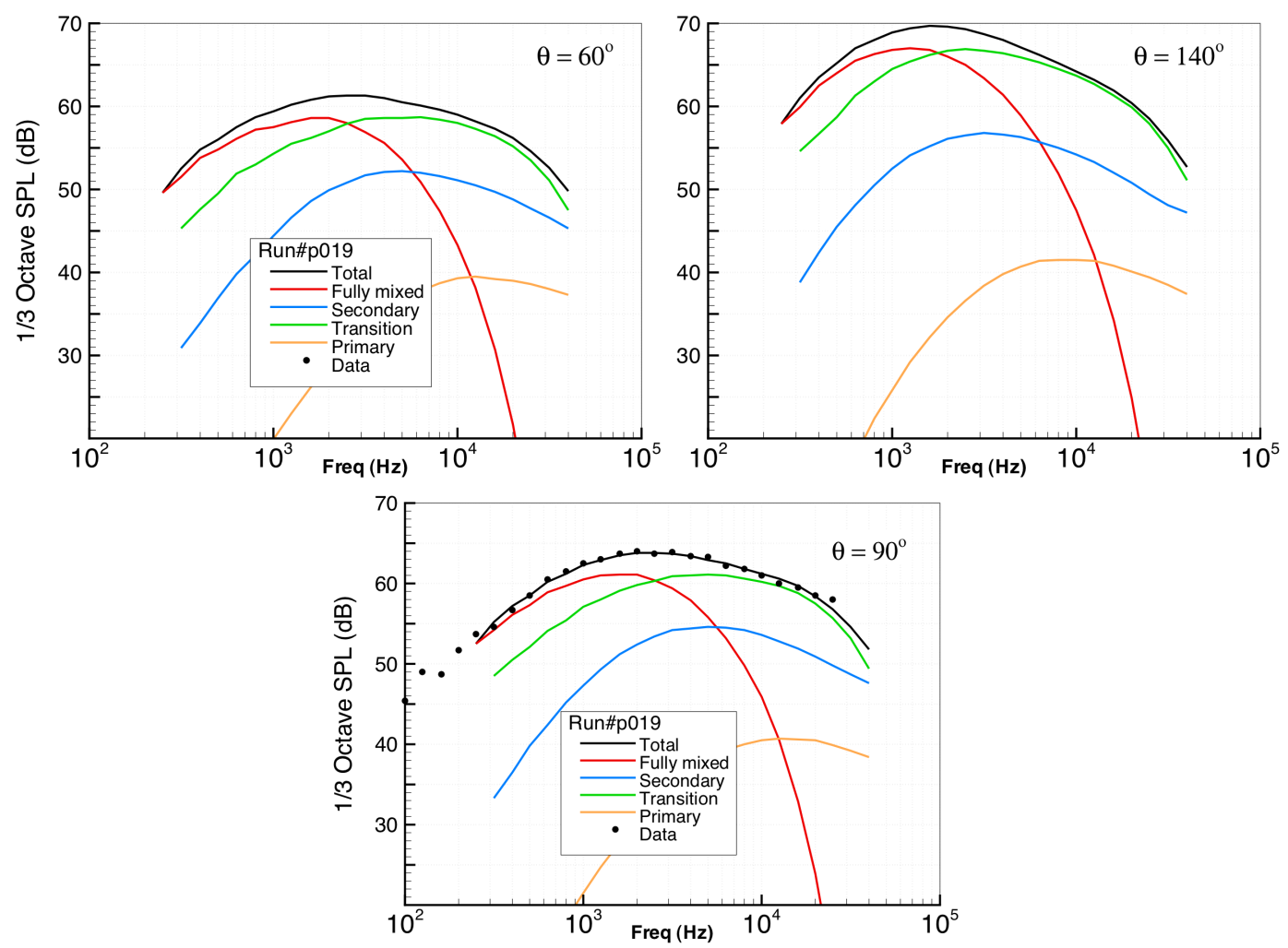

Figure 7.- Jet noise spectrum in dual stream unheated jets at $60^{\circ}, 90^{\circ}$ and $140^{\circ}$ (Run no. P019, Table 1) $T_{p}^{o} / T_{\infty}=1.0, \lambda_{v}=0.64, U_{p}=701.2 \mathrm{fps}$.
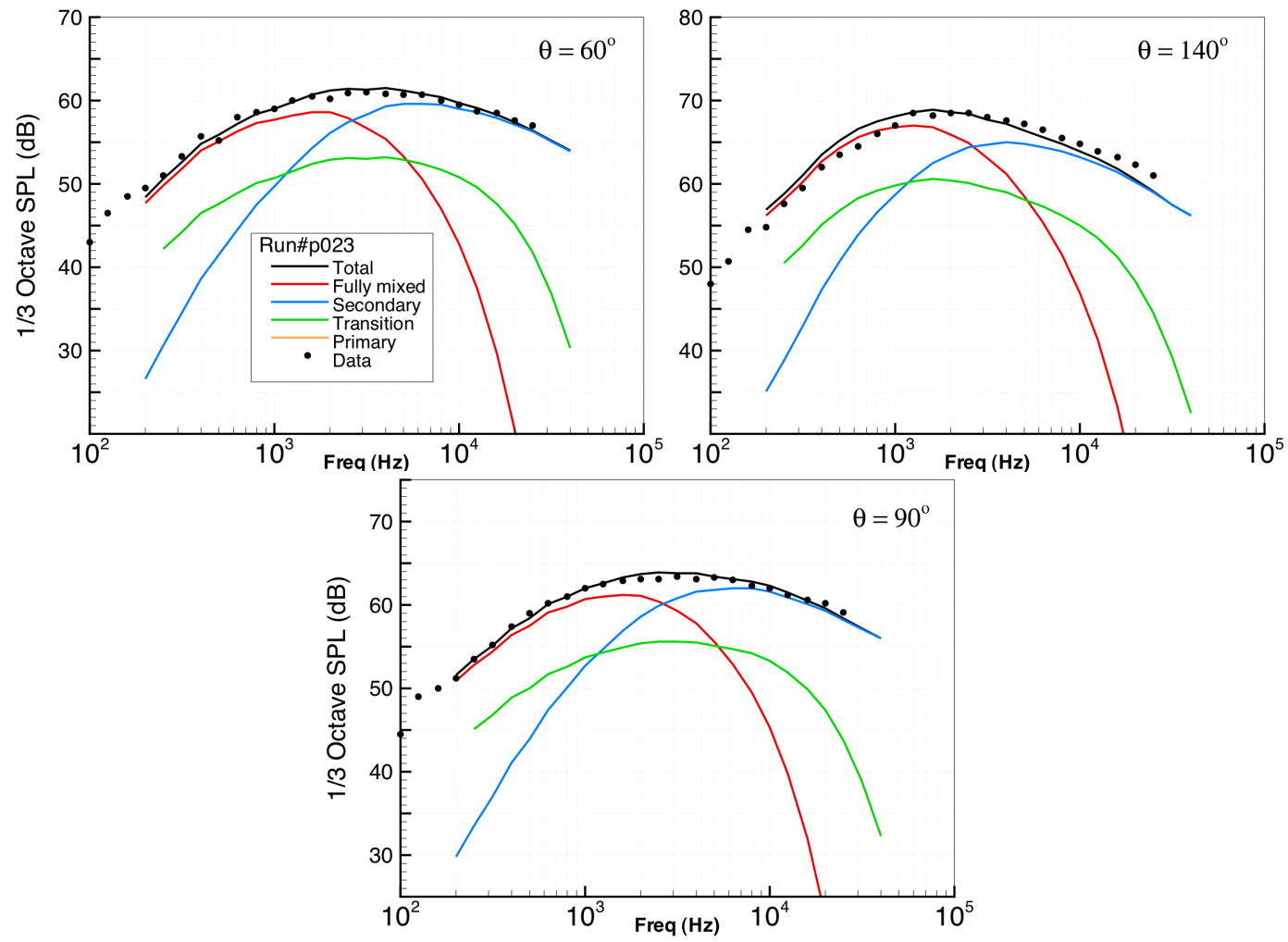

Figure 8.- Jet noise spectrum in dual stream unheated jets at $60^{\circ}, 90^{\circ}$ and $140^{\circ}$ (Run no. P023, Table 1) $T_{p}^{o} / T_{\infty}=1.0, \lambda_{v}=0.99, U_{p}=561.5 \mathrm{fps}$. 

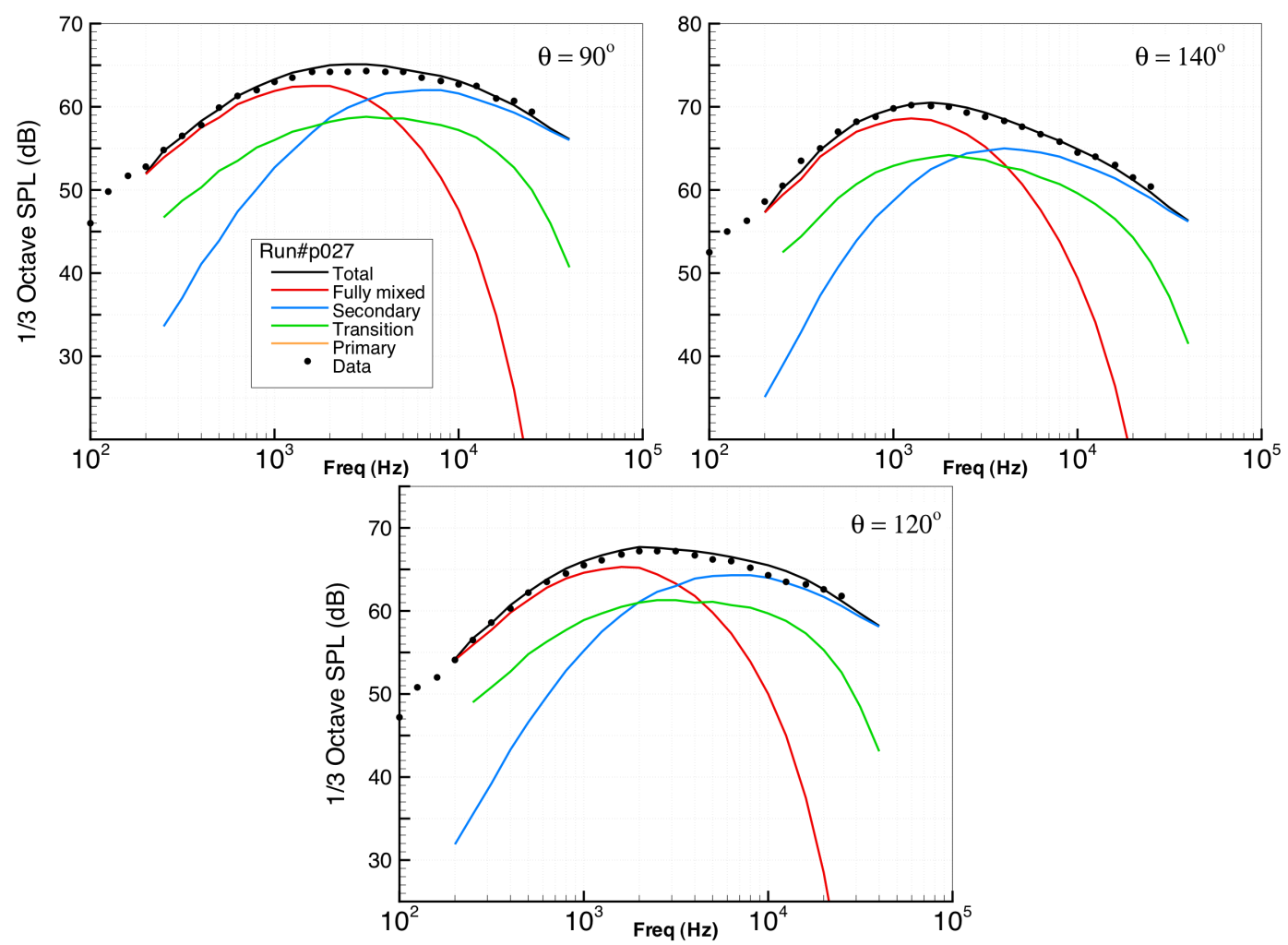

Figure 9.-Jet noise spectrum in dual stream unheated jets at $90^{\circ}, 120^{\circ}$ and $140^{\circ}$ (Run no. P027, Table 1) $T_{p}^{o} / T_{\infty}=1.0, \lambda_{v}=0.89, U_{p}=626.8 \mathrm{fps}$.
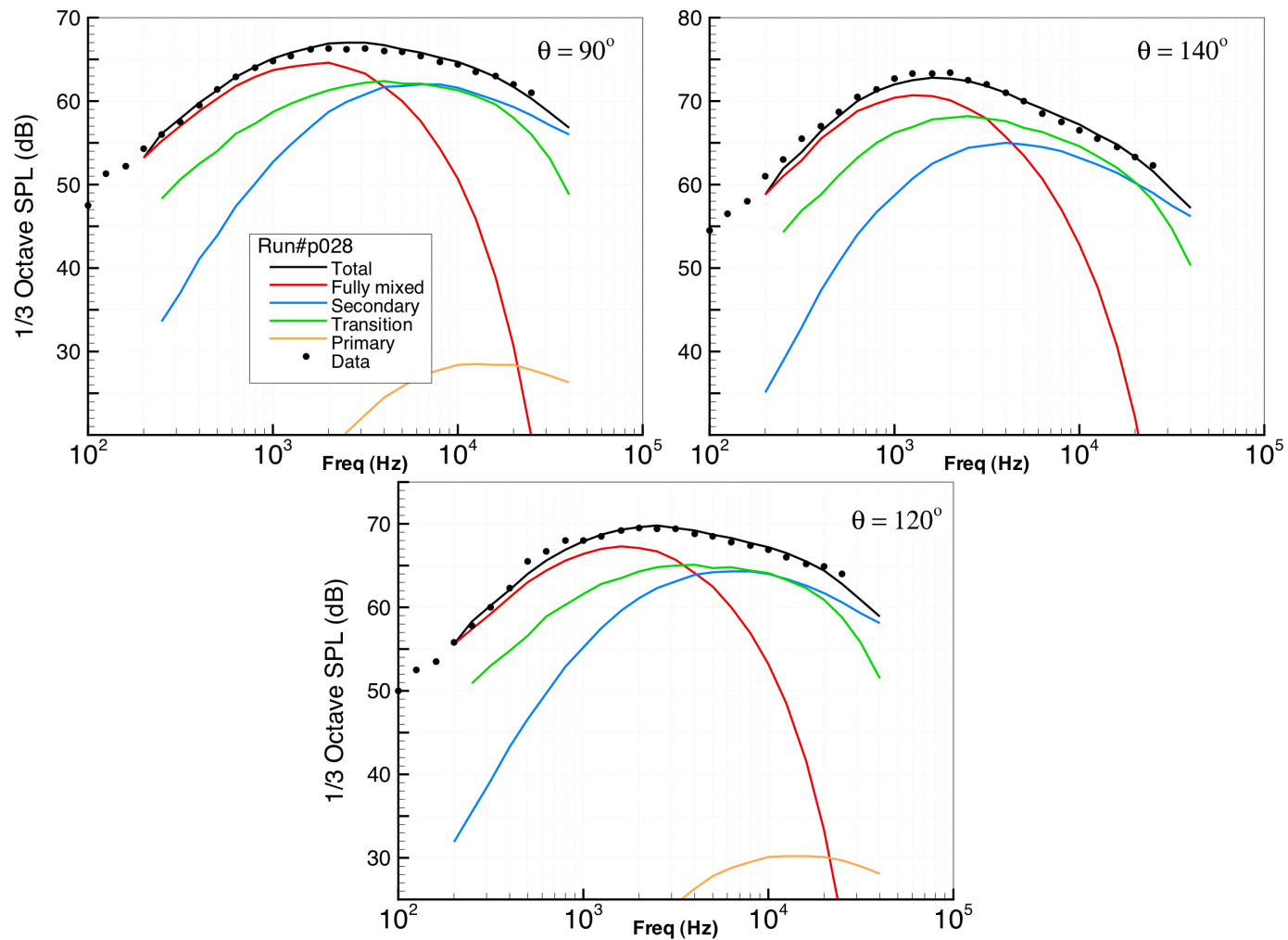

Figure 10.-Jet noise spectrum in dual stream unheated jets at $90^{\circ}, 120^{\circ}$ and $140^{\circ}$ (Run no. P028, Table 1) $T_{p}^{o} / T_{\infty}=1.0, \lambda_{v}=0.79, U_{p}=708.5 \mathrm{fps}$. 

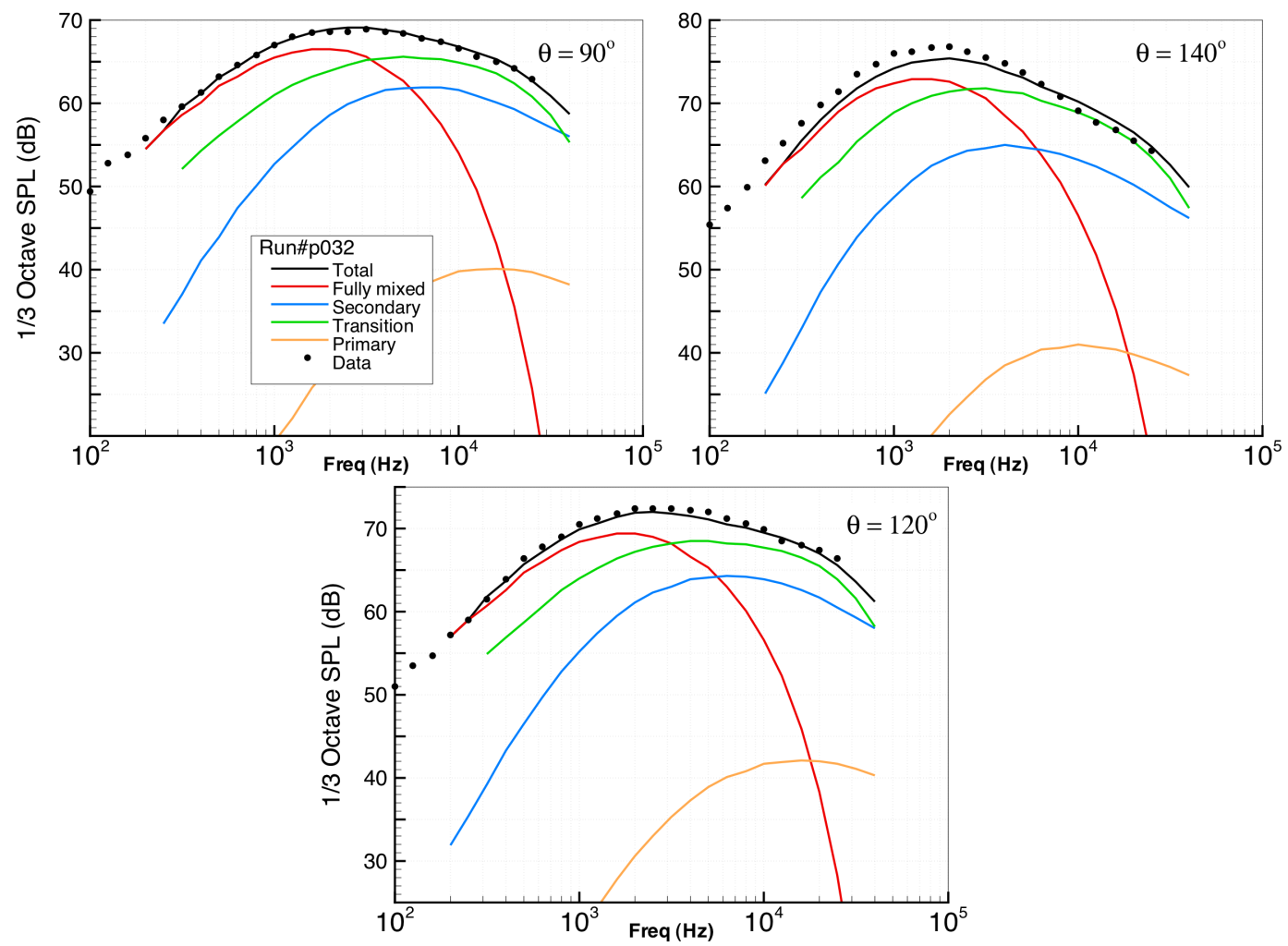

Figure 11.-Jet noise spectrum in dual stream unheated jets at $90^{\circ}, 120^{\circ}$ and $140^{\circ}$ (Run no. P032, Table 1) $T_{p}^{\circ} / T_{\infty}=1.0, \lambda_{v}=0.70, U_{p}=791.8 \mathrm{fps}$.
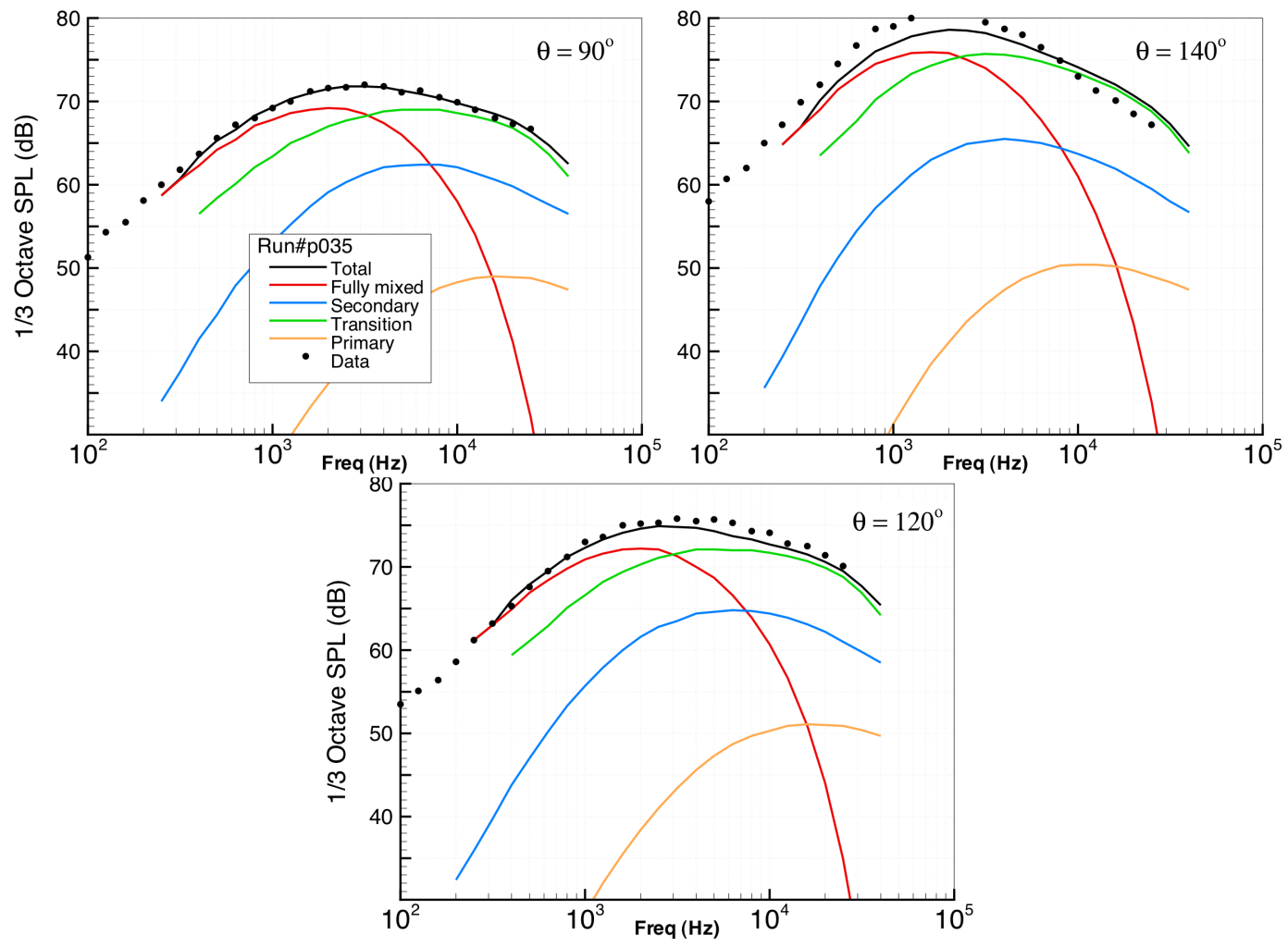

Figure 12.-Jet noise spectrum in dual stream unheated jets at $90^{\circ}, 120^{\circ}$ and $140^{\circ}$ (Run no. P035, Table 1) $T_{p}^{o} / T_{\infty}=1.0, \lambda_{v}=0.63, U_{p}=876.4 \mathrm{fps}$. 

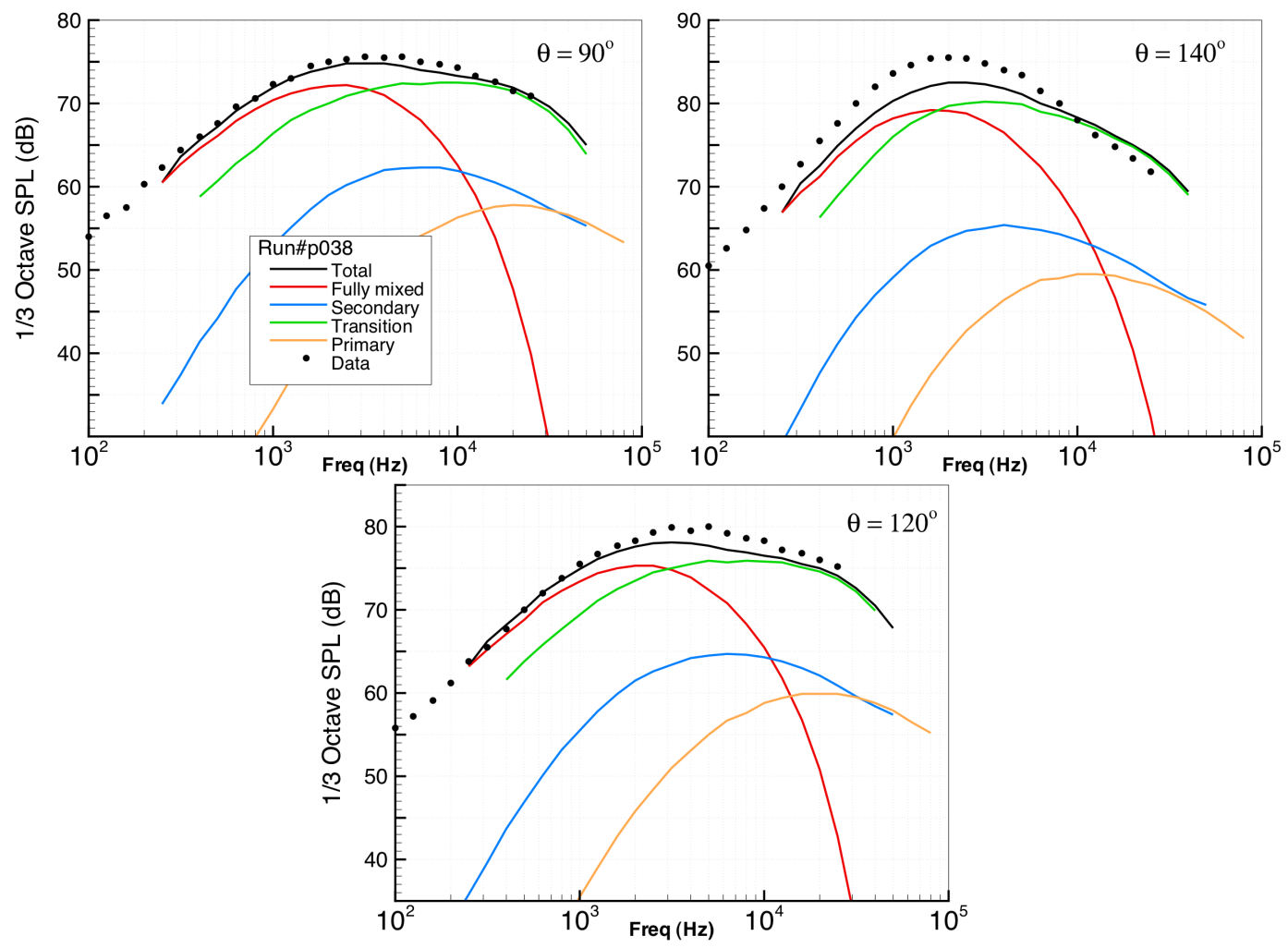

Figure 13.-Jet noise spectrum in dual stream unheated jets at $90^{\circ}, 120^{\circ}$ and $140^{\circ}$ (Run no. P038, Table 1) $T_{p}^{o} / T_{\infty}=1.0, \lambda_{v}=0.56, U_{p}=990.2 \mathrm{fps}$.
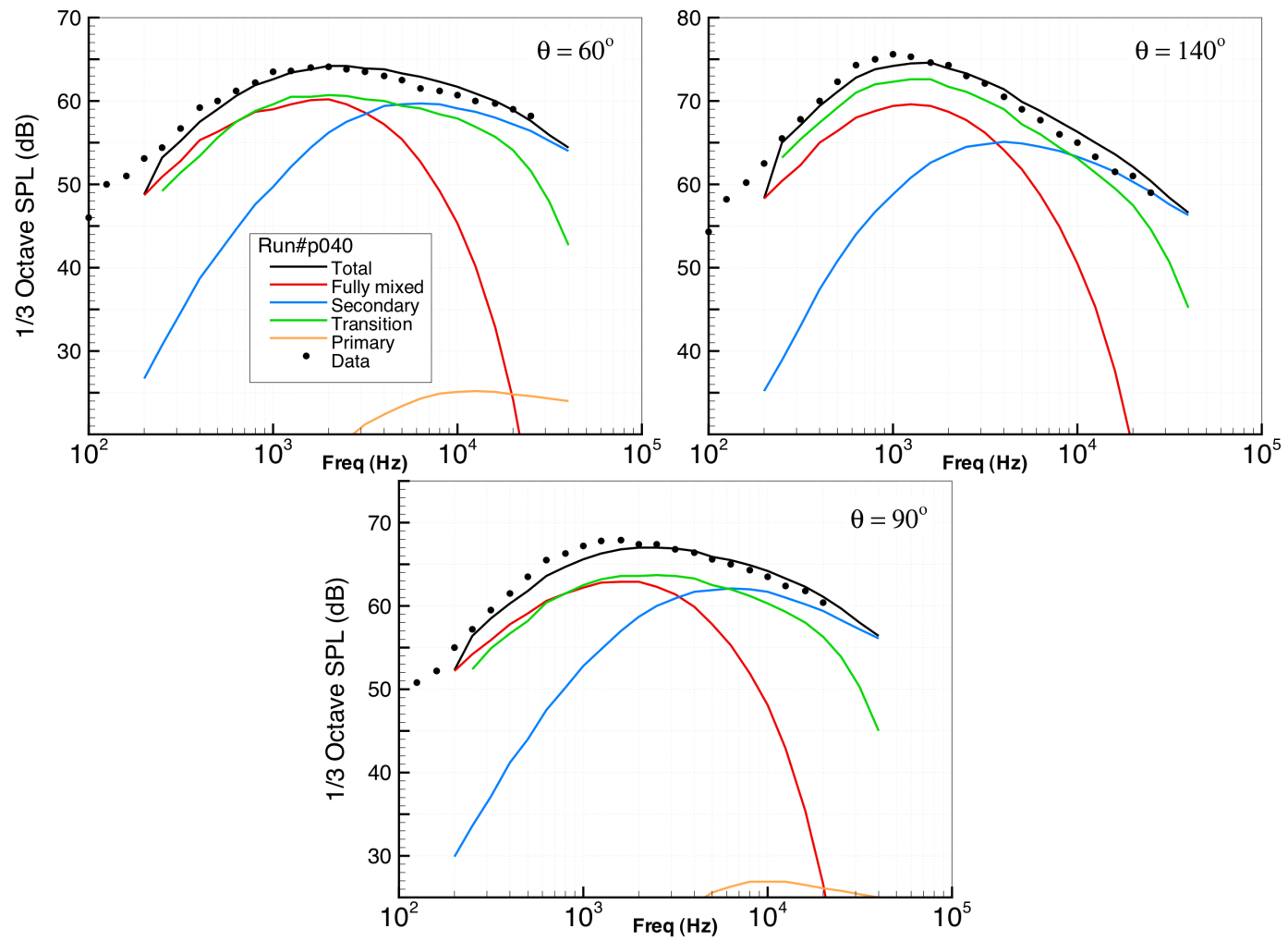

Figure 14.-Jet noise spectrum in dual stream heated jets at $60^{\circ}, 90^{\circ}$ and $140^{\circ}$ (Run no. P040, Table 1) $T_{p}^{o} / T_{\infty}=2.0, \lambda_{v}=0.79, U_{p}=705.2 \mathrm{fps}$. 

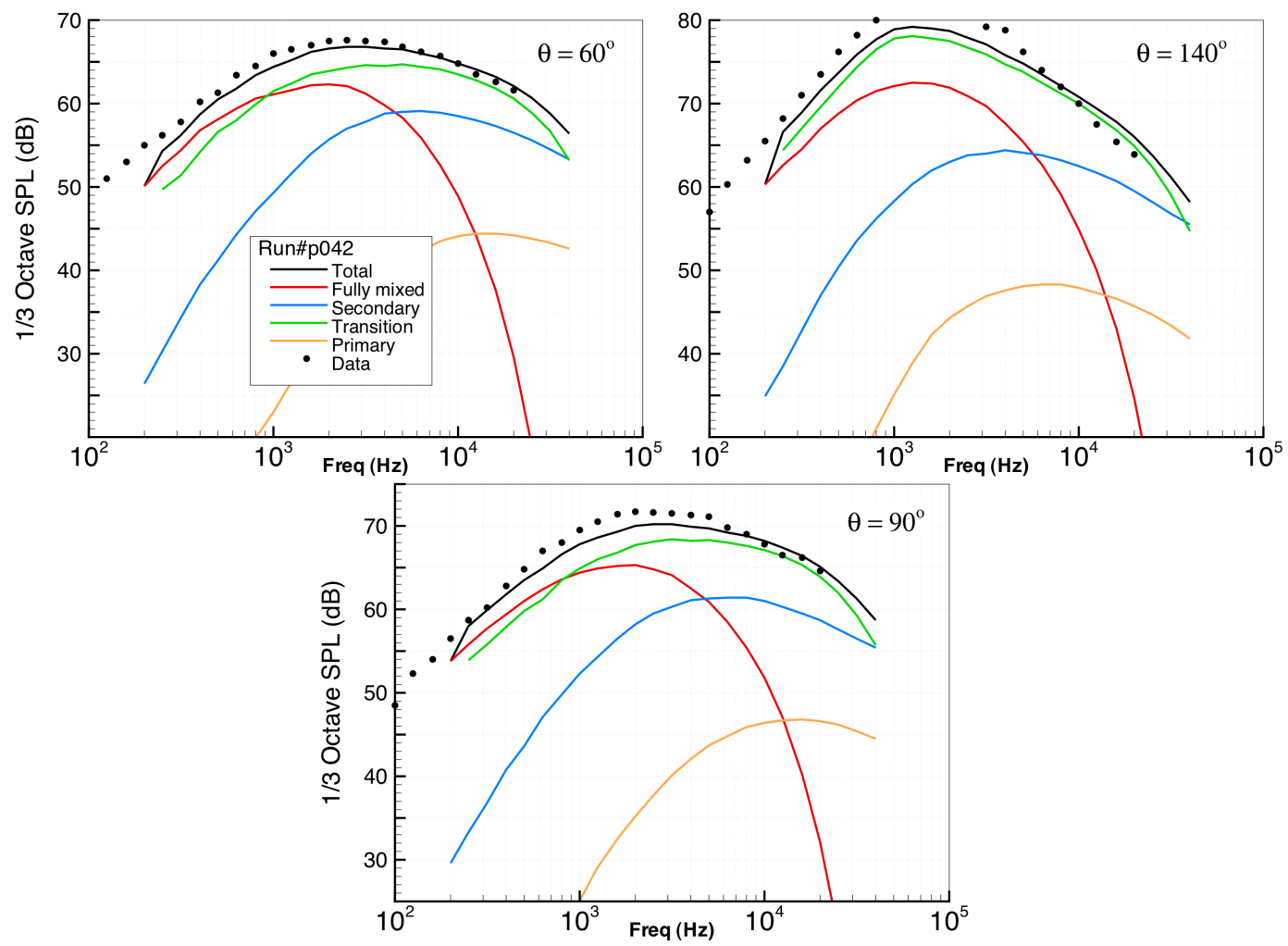

Figure 15.-Jet noise spectrum in dual stream heated jets at $60^{\circ}, 90^{\circ}$ and $140^{\circ}$ (Run no. P042,

Table 1) $T_{p}^{o} / T_{\infty}=2.0, \lambda_{v}=0.63, U_{p}=869.2 \mathrm{fps}$.
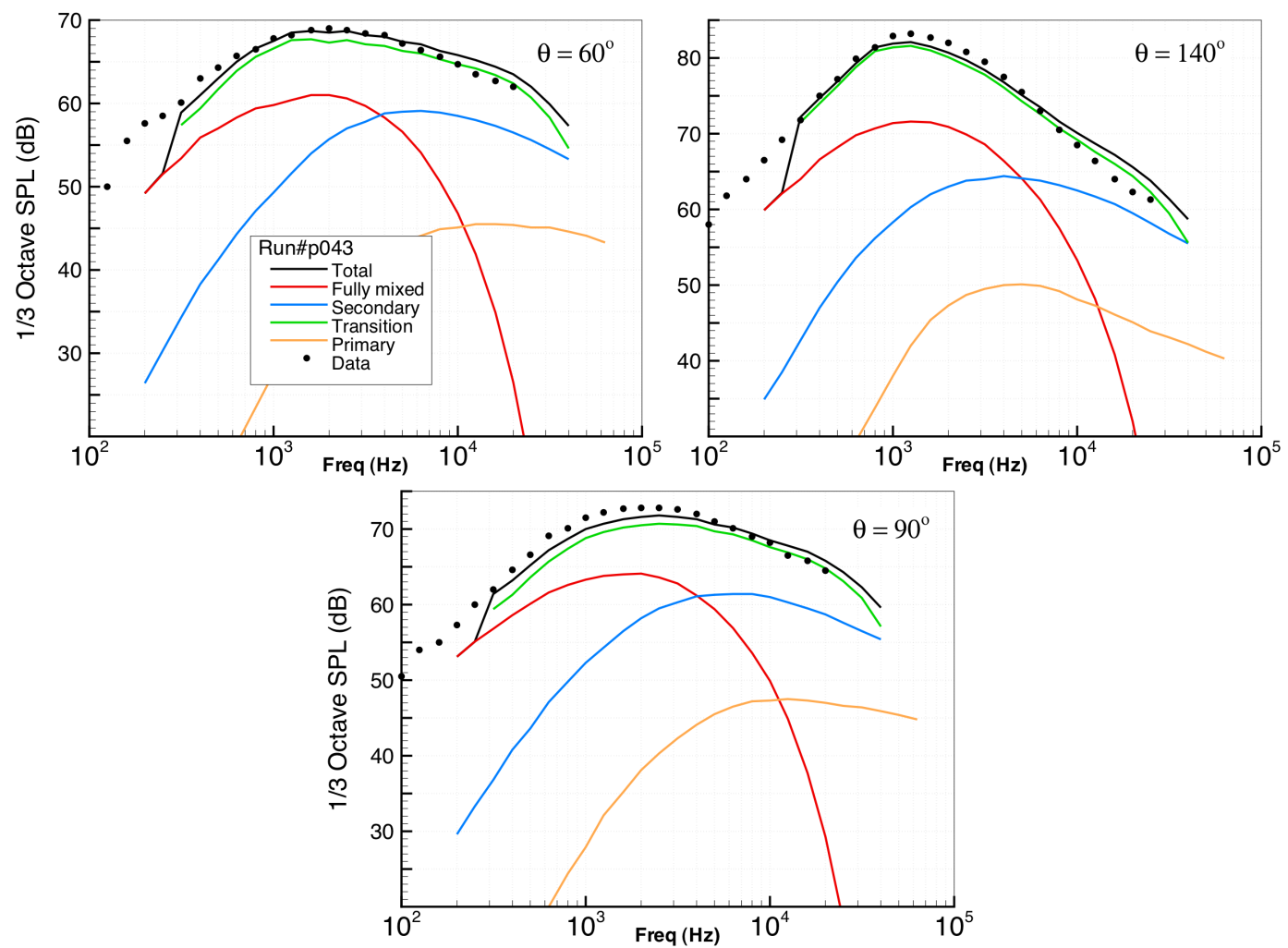

Figure 16.-Jet noise spectrum in dual stream heated jets at $60^{\circ}, 90^{\circ}$ and $140^{\circ}$ (Run no. P043,

Table 1) $T_{p}^{o} / T_{\infty}=2.67, \lambda_{v}=0.63, U_{p}=869.2 \mathrm{fps}$. 

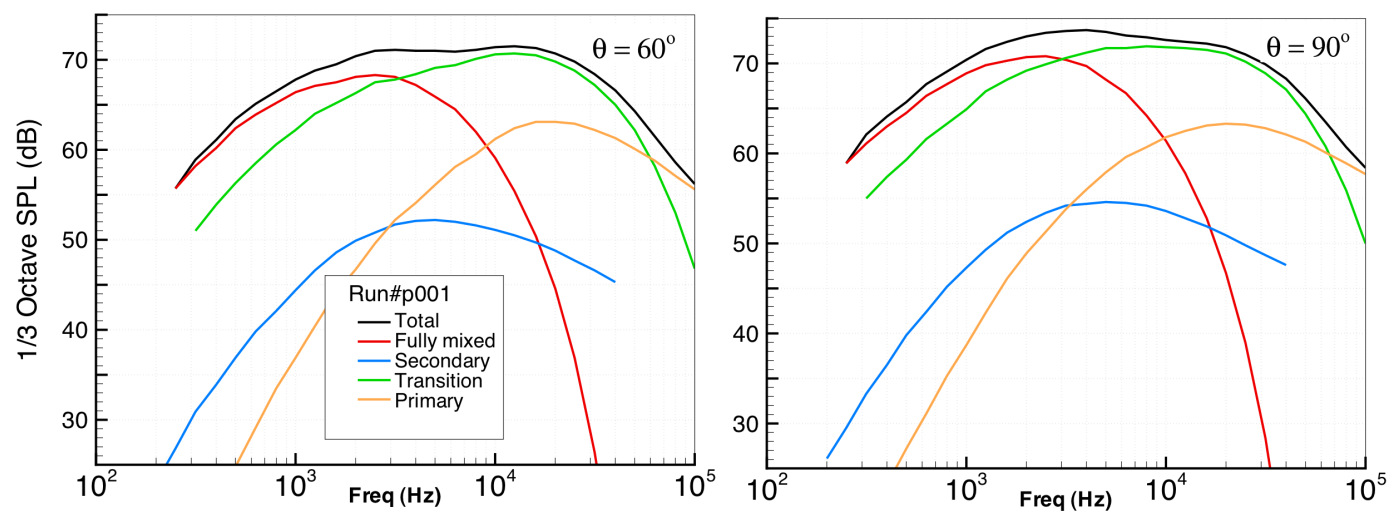

Figure 17.-Predicted jet noise spectrum in dual stream unheated jets at $60^{\circ}$ and $90^{\circ}$ (Run no. P001, Table 2) $T_{p}^{o} / T_{\infty}=1.0, \lambda_{v}=0.45, U_{p}=997.5 \mathrm{fps}$.

The prediction model presented here, although quite satisfactory for the test cases examined, remains to be validated at other conditions with larger area ratio $\lambda_{A}$ typical of turbofan engines at high bypass ratio $B P R>8$. Also of interest would be jet noise spectral data in dual stream flows with a heated secondary. In such flows, the radial temperature gradient in the bypass stream is expected to enhance the refraction of the high-frequency noise and provide a so-called thermal shielding.

\subsection{Summary}

A jet noise prediction model has been proposed for coaxial dual stream flows that should find application in turbofan engines. The model uses a composite of four equivalent single-stream jets, each subject to an appropriate filter. Reasonably accurate spectra were produced at all test conditions examined in this article. The maximum bypass ratio was about 3.37 at a secondary-to-primary area ratio of 2.0. The velocity ratio spanned a wide range of 0.45 to 1.42 . The component spectra show that the secondary stream completely dominates the mid- to high-frequency noise at the highest velocity ratio. The large turbulence scales in the fully mixed region of the jet mostly dominated the low-frequency noise. The model relied on quality noise prediction in single-stream jets at both heated and unheated conditions. Subsequently, no special provisions were needed to account for the temperature effect. High bypass ratio jets, and jets with a heated secondary remain to be tested to further validate the model and its filter functions.

Of near-term interest is the extension of the model to dual stream jets with a supersonic primary and/or secondary, where shock-cell formation and the broadband shock associated noise should additionally be taken into consideration. As pointed out in the introduction, the prediction model is intended to provide a quick and reasonably accurate noise assessment in coaxial, axisymmetric, dual stream configurations, and is, in no way, intended to identify or assess noise benefit/penalty of various noise suppression devices. Those concepts need to be studied and possibly modeled in a similar fashion within their own parametric space. In such cases, a physics-based jet noise predictions methodology that deploys a variant of the Acoustic Analogy, or large eddy simulation may suggest trends that could help engine designers with their noise mitigation efforts.

\section{References}

1. Bridges, J. and Brown, C.A., "Validation of the Small Hot Jet Rig for Jet Noise Research," AIAA2005-2846, May 2005.

2. Brown, C.A., and Bridges, J., "Small Hot Jet Acoustic Rig Validation," NASA/TM-2006-214234, 2006. 
3. Bridges, J., and Wernet, M.P., "Effect of Temperature on Jet Velocity Spectra," AIAA-2007-3628, 2007.

4. Khavaran, A., and Bridges, J., "SHJAR Jet Noise Data and Power Spectral Laws," NASA/TM2009-215608, http://gltrs.grc.nasa.gov, March 2009.

5. Khavaran, A., and Bridges, J., "Development of Jet Noise Power Spectral Laws Using SHJAR Data," AIAA-2009-3378, May 2009.

6. Stone, J.R., Krejsa, E.A. and Clark, B.J., "Jet Noise Modeling for Coannular Nozzles Including the Effects of Chevrons," NASA/CR - 2003-212522, http://gltrs.grc.nasa.gov, September 2009

7. Stone, J.R., Krejsa, E.A. and Clark, B.J., "Semi-Empirical Model for Coannular Nozzle Component Noise Extraction and Correlation Including the Effects of Noise Reduction Devices," AIAA-20031060, 2003.

8. Fisher, M.J., and Preston, G.A., and Bryce, W.D., "A Modeling of the Noise from Simple Co-axial Jets," AIAA-1993-4413, October 1993.

9. Fisher, M. J., and Preston, G. A., and Mead, C. J., "A Modeling of Noise from Simple Coaxial Jets," AIAA-1996-1666, May 1996.

10. Ko, N.W.M., and Kwan, S.H., "The Initial Region of Subsonic Coaxial Jets," J. Fluid Mechanics, 73(2), pp. 305-332, 1976.

11. Abramovich, N., The Theory of Turbulent Jets, M.I.T. Press, 1963.

12. Eldred, K.M., et al., "Far-field noise Generation by Coaxial Flow Jet Exhaust. 1. Detailed Discussion," Wyle Lab Report FAA-RD-71-101, 1971.

13. Khavaran A., and Kenzakowski, D.C., "Noise Generation in Hot Jets," AIAA-2007-3640, 2007.

14. Viswanathan, K., "Parametric Study of Noise from Dual Stream Nozzles," J. Fluid Mechanics, 521, pp. $35-68,2004$.

15. Fisher, M.J., and Preston, G.A., "The Prediction of Noise from Co-axial Jets," ISVR Technical Report No. 215, University of Southampton, 1993. 


\begin{tabular}{|c|c|c|}
\hline \multicolumn{2}{|c|}{ REPORT DOCUMENTATION PAGE } & $\begin{array}{l}\text { Form Approved } \\
\text { OMB No. 0704-0188 }\end{array}$ \\
\hline \multicolumn{3}{|c|}{$\begin{array}{l}\text { The public reporting burden for this collection of information is estimated to average } 1 \text { hour per response, including the time for reviewing instructions, searching existing data sources, gathering and maintaining the } \\
\text { data needed, and completing and reviewing the collection of information. Send comments regarding this burden estimate or any other aspect of this collection of information, including suggestions for reducing this } \\
\text { burden, to Department of Defense, Washington Headquarters Services, Directorate for Information Operations and Reports (0704-0188), 1215 Jefferson Davis Highway, Suite } 1204 \text {, Arlington, VA } 22202-4302 \text {. } \\
\text { Respondents should be aware that notwithstanding any other provision of law, no person shall be subject to any penalty for failing to comply with a collection of information if it does not display a currently valid OMB } \\
\text { control number. } \\
\text { PLEASE DO NOT RETURN YOUR FORM TO THE ABOVE ADDRESS. }\end{array}$} \\
\hline $\begin{array}{l}\text { 1. REPORT DATE (DD-MM-YYYY) } \\
01-11-2010\end{array}$ & $\begin{array}{l}\text { 2. REPORT TYPE } \\
\text { Technical Memorandum }\end{array}$ & 3. DATES COVERED (From - To) \\
\hline \multirow{3}{*}{\multicolumn{2}{|c|}{$\begin{array}{l}\text { 4. TITLE AND SUBTITLE } \\
\text { Jet Noise Scaling in Dual Stream Nozzles }\end{array}$}} & 5a. CONTRACT NUMBER \\
\hline & & 5b. GRANT NUMBER \\
\hline & & 5c. PROGRAM ELEMENT NUMBER \\
\hline \multirow{3}{*}{\multicolumn{2}{|c|}{$\begin{array}{l}\text { 6. AUTHOR(S) } \\
\text { Khavaran, Abbas; Bridges, James }\end{array}$}} & 5d. PROJECT NUMBER \\
\hline & & 5e. TASK NUMBER \\
\hline & & $\begin{array}{l}\text { 5f. WORK UNIT NUMBER } \\
\text { WBS 561581.02.08.03.18.03 }\end{array}$ \\
\hline \multicolumn{2}{|c|}{$\begin{array}{l}\text { 7. PERFORMING ORGANIZATION NAME(S) AND ADDRESS(ES) } \\
\text { National Aeronautics and Space Administration } \\
\text { John H. Glenn Research Center at Lewis Field } \\
\text { Cleveland, Ohio 44135-3191 }\end{array}$} & $\begin{array}{l}\text { 8. PERFORMING ORGANIZATION } \\
\text { REPORT NUMBER } \\
\text { E-17466 }\end{array}$ \\
\hline \multirow{2}{*}{\multicolumn{2}{|c|}{$\begin{array}{l}\text { 9. SPONSORING/MONITORING AGENCY NAME(S) AND ADDRESS(ES) } \\
\text { National Aeronautics and Space Administration } \\
\text { Washington, DC 20546-0001 }\end{array}$}} & $\begin{array}{l}\text { 10. SPONSORING/MONITOR'S } \\
\text { ACRONYM(S) } \\
\text { NASA }\end{array}$ \\
\hline & & $\begin{array}{l}\text { 11. SPONSORING/MONITORING } \\
\text { REPORT NUMBER } \\
\text { NASA/TM-2010-216887 }\end{array}$ \\
\hline \multicolumn{3}{|c|}{$\begin{array}{l}\text { 12. DISTRIBUTIONIAVAILABILITY STATEMENT } \\
\text { Unclassified-Unlimited } \\
\text { Subject Category: } 07 \\
\text { Available electronically at http://gltrs.grc.nasa.gov } \\
\text { This publication is available from the NASA Center for AeroSpace Information, 443-757-5802 }\end{array}$} \\
\hline
\end{tabular}

\section{SUPPLEMENTARY NOTES}

\section{ABSTRACT}

Power spectral laws in dual stream jets are studied by considering such flows a superposition of appropriate single-stream coaxial jets. Noise generation in each mixing region is modeled using spectral power laws developed earlier for single stream jets as a function of jet temperature and observer angle. Similarity arguments indicate that jet noise in dual stream nozzles may be considered as a composite of four single stream jets representing primary/secondary, secondary/ambient, transition, and fully mixed zones. Frequency filter are designed to highlight spectral contribution from each jet. Predictions are provided at an area ratio of 2.0--bypass ratio from 0.80 to 3.40 , and are compared with measurements within a wide range of velocity and temperature ratios. These models suggest that the low frequency noise in unheated jets is dominated by the fully mixed region at all velocity ratios, while the high frequency noise is dominated by the secondary when the velocity ratio is larger than 0.80 . Transition and fully mixed jets equally dominate the low frequency noise in heated jets. At velocity ratios less than 0.50 , the high frequency noise from primary/bypass becomes a significant contributing factor similar to that in the secondary/ambient jet.

\section{SUBJECT TERMS}

Noise; Aircraft noise; Aerodynamic noise; Acoustics

\begin{tabular}{|c|c|c|c|c|c|}
\hline \multicolumn{3}{|c|}{ 16. SECURITY CLASSIFICATION OF: } & \multirow{2}{*}{$\begin{array}{l}\text { 17. LIMITATION OF } \\
\text { ABSTRACT } \\
\text { UU }\end{array}$} & \multirow{2}{*}{$\begin{array}{l}\text { 18. NUMBER } \\
\text { OF } \\
\text { PAGES } \\
25\end{array}$} & \multirow{2}{*}{$\begin{array}{l}\text { 19a. NAME OF RESPONSIBLE PERSON } \\
\text { STI Help Desk (email:help@sti.nasa.gov) } \\
\text { 19b. TELEPHONE NUMBER (include area code) } \\
\text { 443-757-5802 }\end{array}$} \\
\hline $\begin{array}{l}\text { a. REPORT } \\
U\end{array}$ & $\begin{array}{l}\text { b. ABSTRACT } \\
U\end{array}$ & $\begin{array}{l}\text { c. THIS } \\
\text { PAGE } \\
\text { U }\end{array}$ & & & \\
\hline
\end{tabular}



